\title{
Molecular mechanisms of radiation resistance in doxorubicin-resistant breast adenocarcinoma cells
}

\author{
LIDIA LUZHNA $^{1}$, ANDREY GOLUBOV ${ }^{1}$, SLAVA ILNYTSKYY ${ }^{1}$, VASYL F. CHEKHUN ${ }^{2}$ and OLGA KOVALCHUK ${ }^{1}$ \\ ${ }^{1}$ Department of Biological Sciences, University of Lethbridge, Lethbridge, AB T1K3M4, Canada; \\ ${ }^{2}$ Department of Mechanisms of Anticancer Therapy, R.E. Kavetsky Institute of Experimental Pathology, \\ Oncology and Radiobiology of the National Academy of Sciences (NAS) of Ukraine, Kiev 03022, Ukraine
}

Received November 6, 2012; Accepted December 21, 2012

DOI: $10.3892 /$ ijo.2013.1845

\begin{abstract}
A positive response to breast cancer treatment is largely dependent on the successful combination of anticancer treatment modalities, such as chemotherapy and radiation therapy. Unfortunately, chemotherapy resistance occurs frequently. Furthermore, drug-resistant tumors can become unresponsive to other antitumor therapies, and they often fail to respond to radiation therapy. The molecular structures underlying the radiation responses of chemoresistant cells and tumors are not well understood. We analyzed the effect of ionizing radiation on $\mathrm{MCF}-7$ human breast adenocarcinoma cells and their doxorubicin-resistant variant, MCF-7/DOX. The results demonstrated that drug-resistant MCF-7/DOX cells were less susceptible to radiation-induced DNA damage and apoptosis. This was proven through gene expression profiling, lower levels of $\gamma \mathrm{H} 2 \mathrm{AX}$ foci upon irradiation, and altered levels of DNA repair proteins, including pATM, KU70 and RAD51. Additionally, MCF-7/DOX drug-resistant cells harbored DNA polymerases with significantly low fidelity. In summary, our study revealed that drug-resistant MCF-7/DOX cells have high DNA repair potential and low-fidelity DNA polymerases, seemingly sacrificing specificity and efficiency to gain higher survival potential. In the long run, this may lead to an increased probability of mutation accumulation and further the development of an even more pronounced resistance phenotype. Therefore, this study provides a roadmap for the analysis of the roles of the DNA repair function and effectiveness, and apoptosis in response to radiation, chemotherapy and combinations of both treatment modalities.
\end{abstract}

Correspondence to: Dr Olga Kovalchuk, Department of Biological Sciences, University of Lethbridge, 4401 University Drive, Lethbridge, AB T1K 3M4, Canada

E-mail: olga.kovalchuk@uleth.ca

Abbreviations: IR, ionizing radiation; DSB, double strand DNA break; HR, homologous recombination; NHEJ, non-homologous end-joining

Key words: breast cancer, drug resistance, radiation response, DNA repair, $\gamma \mathrm{H} 2 \mathrm{AX}$

\section{Introduction}

Systemic chemotherapy is an important breast cancer treatment modality and its effectiveness has significantly improved over the last decade (1). Notwithstanding, the development of cancer cells that are resistant to chemotherapeutic agents is a major clinical obstacle in the successful treatment of breast cancer $(2,3)$. Understanding the structures underlying drug resistance development and predisposition is critical to saving lives.

Overall, acquired drug resistance is a multi-factorial phenomenon that involves multiple structures and processes (2-5), including: a decreased uptake of drugs (6), alterations in cell cycle and signal transduction pathways $(7,8)$, increased repair of DNA damage (9), reduced apoptosis $(7,10,11)$, increased efflux of hydrophobic drugs $(5,6,8,12,13)$ and DNA damage tolerance (9). Resistance to individual chemotherapeutic agents usually occurs through alterations in the drug targets, but broad resistance can also occur, affecting the utility of a variety of diverse and unrelated antitumor drugs with different chemical structures and different mechanisms of action $(5,12,14-16)$. Apoptosis avoidance is one of the key processes underlying multiple drug resistance phenotypes $(7,10,11,17)$.

Doxorubicin is an anthracycline drug frequently used in the curative-intent, adjuvant therapy and palliative treatment of metastatic breast cancer (18). Although doxorubicin is among the most active agents in breast cancer treatment, many patients will experience a relapse after the drug therapy is completed. Furthermore, approximately half of metastatic breast cancer patients will fail to respond to doxorubicin entirely, and the majority of those showing initial benefits will subsequently manifest acquired clinical resistance demonstrated by tumor growth that will occur despite ongoing anthracycline therapy (18).

It has also been reported that drug-resistant cancer cells may fail to respond to cytotoxic radiotherapy and may develop a multidrug-resistant phenotype (19-27). However, the data on the radiation responses of chemoresistant tumors is contradictory. For instance, some clinical studies suggest significant benefits from a combination of chemo- and radiotherapy for breast cancer management (28). On the other hand, there is proof that chemotherapy used as an induction therapy before radiotherapy has no significant additional antitumor effects (29). Breast tumors tend to resist and reoccur after the aforementioned 
treatments (30). The exact nature and structure of the radiation responses of chemoresistant tumor cells remain unclear.

One of the key features of cancer cell resistance to therapeutic agents is their associated resistance to apoptotic cell death (7). Chemoresistant cells and tumors have a strong capacity to withstand and avoid apoptosis during chemotherapy treatment $(7,31)$. Ionizing radiation (IR) exposure is known to induce apoptosis in exposed cells, yet little is known about the status of IR-induced apoptosis in drug-resistant cell lines.

In this study, we analyzed the cellular and molecular structures of radiation responses in MCF-7 breast adenocarcinoma cells and their derivative line that is resistant to doxorubicin (MCF-7/DOX). For the first time, we show that MCF-7/DOX cells, while harboring an elevated potential to withstand radiation-induced DNA damage, also have a significantly decreased fidelity of DNA polymerases and a delayed radiation-induced apoptosis.

\section{Materials and methods}

Cell lines and cell culture conditions. MCF-7 and MCF-7/DOX multidrug-resistant human breast adenocarcinoma cell lines were previously developed and described elsewhere $(17,32)$. Cells were grown and maintained in Dulbecco's modified Eagle's medium (DMEM/F-12) with $2.5 \mathrm{mM}$ L-glutamine, without HEPES and Phenol Red (HyClone, Logan, UT), supplemented with $10 \%$ heat-inactivated fetal bovine serum (HyClone), in the presence of antibiotics $100 \mathrm{U} / \mathrm{ml}$ penicillin and $100 \mu \mathrm{g} / \mathrm{ml}$ streptomycin (Sigma-Aldrich Chemical Co., St. Louis, MO), and in a $5 \% \mathrm{CO}_{2}$ atmosphere at $37^{\circ} \mathrm{C}$. Cells were harvested for analyses by trypsinization $(17,32)$.

Irradiation conditions. Cells were irradiated at a $60 \%$ confluency in DMEM. Two radiation doses $(0.5$ and $5 \mathrm{~Gy}, 90 \mathrm{kVp}$, $5 \mathrm{~mA}$ ) were applied to check the cellular radiation responses. Unirradiated cells served as the control. Cells were harvested $30 \mathrm{~min}, 24$ and $48 \mathrm{~h}$ after irradiation. All the cells were tested in triplicate. The experiments were independently reproduced twice.

\section{Whole-genome gene expression profiling}

RNA isolation. Total RNA was isolated using the Illustra RNAspin mini kit (GE Healthcare Life Sciences, Buckinghamshire, UK). Approximately $5 \times 10^{6}$ cultured cells were processed following the manufacturer's instructions. Samples were eluted in Ultrapure DNase/RNase-free distilled water, which was provided in the kit. RNA samples were quantified using ultraviolet spectroscopy (NanoDrop, Wilmington, $\mathrm{DE}$ ) and were further assessed for RNA integrity (RIN) on the Agilent 2100 Bioanalyzer (Santa Clara, CA) using the RNA Nano-chip Kit. RNA samples with RIN values of seven or better were used for the further analysis.

Library preparation. CRNA was created using the Ambion's Illumina TotalPrep RNA Amplification Kit (Applied Biosystems, Carlsbad, CA) with an input of $500 \mathrm{ng}$ of total RNA per sample. Briefly, oligo-dT primers were used to synthesize first strand cDNA containing a phage T7 promoter sequence. Single-stranded cDNA was converted into a double-stranded DNA template via DNA polymerase. RNase $\mathrm{H}$ simultaneously acted to degrade the RNA. Samples of cDNA were purified in filter cartridges to remove excess RNA, primers, enzymes and salts. The recovered cDNA was subjected to in vitro transcription using biotinylated UTPs. This step created, labeled and amplified cRNA. A final purification step removed unincorporated NTPs, salts, inorganic phosphates and enzymes, which prepared the samples for hybridization.

Hybridization and detection. Illumina's direct hybridization assay kit was used to process samples according to the manufacturer's protocol (Illumina, San Diego, CA). Overnight, $750 \mathrm{ng}$ from each cRNA sample was hybridized into the Illumina HumanHT-12_v4 Whole Genome Expression BeadChip arrays. Afterward, a 10-min incubation with a supplied wash buffer at $55^{\circ} \mathrm{C}$ preceded a 5 -min room temperature wash. The arrays were incubated in $100 \%$ ethanol for $10 \mathrm{~min}$. A second room temperature wash lasted 2 min with gentle shaking, which completed this high stringency wash step. The arrays were blocked with a buffer for $10 \mathrm{~min}$ and washed before a 10-min steptavidin-Cy3 (1:1,000) probing. After a 5-min wash at room temperature, the BeadChips were dried and imaged. Six controls were also built into the Whole-Genome Gene Expression Direct Hybridization Assay system to cover aspects of the array experiments, including controls for: the biological specimen (14 probes for housekeeping controls), 3 controls for hybridization (6 probes for Cy3-labeled hybridization, 4 probes for low stringency hybridization, and 1 probe for high stringency hybridization), signal generation (2 probes for biotin control), and approximately 800 probes for negative controls on an 8-sample BeadChip. The arrays were scanned on the iScan platform (Illumina), and data were normalized and scrutinized using Illumina BeadStudio Software.

BeadChip statistical analysis and data processing. The false discovery rate (FDR) was controlled using the BenjaminiHochberg method. The Illumina Custom Model took the FDR into account and was used to analyze the data. Differential gene expression (at least a 1.5-fold change) from non-irradiated cells was determined to be statistically significant if the p-value after the Benjamini-Hochberg method adjustment was lower than 0.05 . The values were transformed to show a $\log 2$ scale.

Lists of regulated transcripts were inserted into the web-based DAVID Bioinformatics Resources 6.7 (NIAID/NIH) Functional Annotation Tool $(33,34)$. This program was used to group genes into functionally relevant categories: metabolic processes, transport, response to stimulus/stress, immune response, apoptosis and cell cycle processes.

Quantitative real-time PCR. Quantitative real-time PCR was performed to confirm the Whole-Genome Gene Expression results for the regulation direction (either up or down) of select genes. Six genes (aurora B, cyclin A, GADD45G, polymerases A, D and E) were selected from the gene list of significantly differentially expressed transcripts, representing a preliminary review of the acquired gene expression data. 18SrRNA was used as a reference gene. All the reactions were performed using cDNA synthesized from the same RNA extraction as the BeadChip experiments, and $500 \mathrm{ng}$ of the sample was used for the Bio-Rad iScript Select cDNA Synthesis kit (Bio-Rad Laboratories, Hercules, CA). Samples were stored at $-20^{\circ} \mathrm{C}$ for long-term storage and at $4^{\circ} \mathrm{C}$ until they were used for subsequent qRT-PCR reactions. 
Primers were designed using the NCBI database and PrimerQuest (Integrated DNA Technologies Inc., Coralville,IA). The following primers were designed: $h A U R K B$ forward primer 5'-TGA GGA GGA AGA CAA TGT GTG GCA-3' and reverse primer 5'-AGG TCT CGT TGT GTG ATG CAC TCT-3'; 18SrRNA reference gene primers 5'-GTC AAG TTC GAC CGT CTT CT-3' and 5'-AGC TTG CGT TGA TTA AGT CC-3'; CCNA2 forward primer 5'-ATG AGC ATG TCA CCG TTC CTC CTT-3' and reverse primer 5'-TCA GCT GGC TTC TTC TGA GCT TCT-3'; $h G A D D 45 G$ forward primer 5'-TGC TGC GAG AAC GAC ATC GAC ATA-3' and reverse primer 5'-TCG AAA TGA GGA TGC AGT GCA GGT-3'; hPOLAl forward primer 5'-GGC AAT GGC TTT GAA ACC AGA CCT-3' and reverse primer 5'-ATG CTG AAA GCC ATC ACG ACA AGC-3'; hPOLDl forward primer 5'-AAC CTG TGT TAC ACC ACG CTC CTT-3' and reverse primer 5'-TCC GCA CTG AGG TCT TCA CAA ACT-3'; hPOLE forward primer 5'-AGA TTG TGC AGA TCA GCG AGA CCA-3' and reverse primer 5'-TTA CCT TGC GAT ACG AAG CAC CCT-3'. Reactions were prepared using $1 \mu \mathrm{l}$ of diluted cDNA, $10 \mathrm{pmol} / \mu \mathrm{l}$ of each forward and reverse primer, and SsoFast EvaGreen Supermix (Bio-Rad Laboratories) prepared according to the manufacturer's instructions. Samples were prepared in triplicate and were run on the Bio-Rad C1000 Thermal Cycler equipped with the CFX96 Real-Time System. The qRT-PCR protocol consisted of denaturation at $95^{\circ} \mathrm{C}$ for $2 \mathrm{~min} ; 43$ cycles of denaturation $\left(95^{\circ} \mathrm{C}, 5 \mathrm{sec}\right)$ and annealing/extension $\left(55^{\circ} \mathrm{C}, 5 \mathrm{sec}\right)$; and a final extension at $65^{\circ} \mathrm{C}$ for $5 \mathrm{sec}$. For every set of primers, annealing temperature optimization, melting curve analysis and a gel analysis of the amplicon were performed. To evaluate PCR efficiency, a standard curve was established using a series of cDNA dilutions. Data were captured and organized using Bio-Rad CFX Manager 2.1 software (Bio-Rad Laboratories).

$q R T-P C R$ statistical analysis. Quantification data from the Bio-Rad CFX Manager software was analyzed using the Pfaffl method in Microsoft Excel (35). Graphs showing a fold change from the sham group were created, and transcript regulation directions (up or downregulation) were matched to the Whole-Genome Gene Expression results.

Western immunoblot analysis. Following radiation treatment, the cells were harvested, washed in PBS, lysed and sonicated in $0.2 \mathrm{ml}$ of $1 \%$ sodium dodecyl sulphate (SDS). The lysates were cleared using centrifugation. The protein content was determined using the Bradford protein determination assay (Bio-Rad Laboratories). Equal amounts of lysate protein were subsequently run on 10-12\% SDS-polyacrylamide gels and transferred to PVDF membranes (GE Healthcare, Baie d'Urfé, QC, Canada).

Western immunoblot analysis was conducted using wellestablished protocols $(32,36)$. The membranes were incubated with antibodies against goat anti-polymerase $\mathrm{\iota}$, mouse anti-polymerase $\varepsilon(1: 1,000$, Santa Cruz Biotechnology Inc., Santa Cruz, CA ), mouse anti-polymerase $\beta$, rabbit anti-polymerase $\delta$ (1:500 dilution, Abcam Inc., Cambridge, MA), mouse anti-phosphoATM (1:500, Cell Signaling Technology Inc., Danvers, MA), mouse anti-Ku-70 and mouse anti-Rad51 (1:1,000, Santa Cruz Biotechnology Inc.). Antibody binding was revealed through incubation with horseradish peroxidase-conjugated secondary antibodies (GE Healthcare, Piscataway, NJ) and the ECL Plus immunoblotting detection system (GE Healthcare).
Chemiluminescence was detected using BioMax MR film (Eastman Kodak, New Haven, CT). Unaltered PVDF membranes were stained with Coomassie Blue (Bio-Rad Laboratories) to prove equal protein loading.

Analysis of DNA polymerase fidelity in MCF-7 and $M C F-7 / D O X$ cells. The DNA polymerase fidelity assay allows the researcher to determine the activity of polymerases on damaged DNA and the quality of the repair synthesis (37). The assay employs a FAM-labeled $15 \mathrm{bp}$ primer as a component of the substrate. Its oligonucleotide can be revealed on a gel. In the assay, different deoxyribonucleotides were added to the reaction mixture to check the ability of polymerases to incorporate the correct and incorrect dNTPs into the template. Any increase in primer weight upon incorporation would indicate higher DNA polymerase activity while a decrease is associated with exonuclease activity. Misincorporation efficiency is associated with changes in DNA polymerase fidelity.

Substrate (templatelprimer complex). In order to produce the substrate for the assay, FAM-labeled 15bp primer was annealed using a 30 bp template (both were PAGE purified). Template: AG030-PAGE 5'-TCATCGAGCATGATCACGTCGTGAC TGGGA-3'. Primer: AG031-PAGE 5'-FAM-TCCCAGTCACG ACGT-3'. The reaction was performed in $1 \mathrm{M}$ Tris- $\mathrm{HCl}(\mathrm{pH} 8.0)$, $\beta$-mercaptoethanol, BSA (100X NEB), $100 \mu \mathrm{M}$ primer and $100 \mu \mathrm{M}$ template, incubated at $95^{\circ} \mathrm{C}$ for $5 \mathrm{~min}$ and slowly cooled at room temperature.

Cell extracts. MCF-7 and MCF-7/DOX control and irradiated (harvested $24 \mathrm{~h}$ after a $5 \mathrm{~Gy} \mathrm{X}$-ray treatment) cells were harvested, washed in 1X PBS, resuspended and sonicated in PBS, and centrifuged at $4^{\circ} \mathrm{C}$ for $10 \mathrm{~min}$ at $14,000 \mathrm{x}$ g. The total protein concentration in the samples was determined using a Bradford Assay (Bio-Rad Laboratories).

A DNA polymerase fidelity assay was carried out according to Gening et al (37). The reaction was performed at $37^{\circ} \mathrm{C}$ for $15 \mathrm{~min}$, and it was quickly frozen afterward. The reaction mixture contained: $50 \mathrm{mM}$ Tris- $\mathrm{HCl}(\mathrm{pH} 8.0), 5 \mathrm{mM} \mathrm{MgCl}$, $1 \mathrm{mM}$ DTT, $70 \mu \mathrm{g}$ of the tested lysate protein, template/primer complex and $2 \mathrm{mM}$ dNTP. When the reaction was stopped, $5 \mu 1$ of each sample was mixed with $10 \mu 1$ of a loading buffer (95\% formamide, $50 \mathrm{mM}$ EDTA, 0.05\% bromophenol blue), incubated at $95^{\circ} \mathrm{C}$ for $3 \mathrm{~min}$ and cooled on ice. The reaction products were separated in $20 \%$ polyacrylamide gel in the presence of an $8 \mathrm{M}$ urea in a Tris-borate buffer at $750 \mathrm{~V}$. PAGE gels were scanned using a Typhoon 9410 imager (excitation $488 \mathrm{~nm}$, emission filter 520 BP 40, PMT $620 \mathrm{~V}$, resolution $50 \mu \mathrm{m}$ ). The intensity of the bands was measured using the ImageQuant 5.2 software program (Molecular Dynamics).

Annexin $V$ assay. For the early detection of apoptosis, an Annexin V-FITC Apoptosis Detection Kit I (BD Biosciences, San Jose, CA) was used according to the manufacturer's protocol. Cells were grown and irradiated as previously described above in Irradiation conditions. The analysis was performed 24 and $48 \mathrm{~h}$ after radiation exposure. Cells were harvested, washed with PBS, resuspended in a $1 \mathrm{X}$ binding buffer, stained with Annexin $\mathrm{V}$ and propidium iodide for $15 \mathrm{~min}$ at $25^{\circ} \mathrm{C}$ in the dark, and analyzed using flow cytometry within $1 \mathrm{~h}$ at the Flow Cytometry Core Facility (University of Calgary, Calgary, AB, 
Canada). The results were represented as a percentage of gated Annexin $\mathrm{V}$ positive cells.

Alkaline comet assay. The alkaline comet assay protocol was based on Olive and Bannath (38) and Tice and Vasques (39) at cometassay.com. The cells that were grown in cultures were trypsinised, collected in 15-ml tubes, and centrifuged for $3 \mathrm{~min}$ at $1,000 \mathrm{x}$ g to form a pellet. Next, the pellet was washed three times with ice cold phosphate-buffered saline (PBS) without $-\mathrm{Ca}^{2+}$ and $-\mathrm{Mg}^{2+}$. Finally, the cells were resuspended in their final concentration of 1,000 cells per $1 \mu 1$ of cell suspension in ice-cold PBS. The cell suspension was stored on ice during the course of the subsequent procedures.

A total of $10 \mu \mathrm{l}$ of cell suspension were mixed with $75 \mu \mathrm{l}$ of $1 \%$ low melting point (LMP) agarose pre-heated to $40^{\circ} \mathrm{C}$, mixed gently through pipetting up and down, and applied to a fully frosted microscope slide (VWR) that was pre-coated with normal melting point agarose. Agarose was overlaid with a cover slip and allowed to solidify for 2 to $3 \mathrm{~min}$ on ice. The removal of the cover slip was followed by an application of $85 \mu \mathrm{l}$ of $1 \% \mathrm{LMP}$ agarose pre-heated to $40^{\circ} \mathrm{C}$ in order to form a protective layer on top of the layer containing the cell suspension. The cover slip was re-positioned and the slides were placed on ice to allow the agarose to solidify.

The cover slips were removed and the slides were placed in a freshly prepared alkaline lysis solution $[2.5 \mathrm{M} \mathrm{NaCl}, 100 \mathrm{mM}$ $\mathrm{Na}_{2}$ EDTA, $10 \mathrm{mM}$ Tris-base, $1 \%$ Triton $\mathrm{X}-100$ and $0.1 \%$ sodium lauroyl sarcosine ( $\mathrm{pH} 10$ ) adjusted to $4^{\circ} \mathrm{C}$ ], left overnight at $4^{\circ} \mathrm{C}$ and protected from light. Following the lysis step, the slides were rinsed with a freshly prepared electrophoresis solution [300 mM, 2 mM EDTA ( $\mathrm{pH}>14)$ ]. Next, the slides were placed in an electrophoresis tank, covered with a thin layer (1-2 mm) of electrophoresis buffer, and left for $30 \mathrm{~min}$ to permit alkaline DNA unwinding. Electrophoresis was performed for $25 \mathrm{~min}$ at $0.7 \mathrm{~V} / \mathrm{cm}$. Each electrophoresis included slides that belonged to the same experimental time-point.

After the completion of the electrophoresis, the slides were washed three times for $5 \mathrm{~min}$ in a neutralization buffer $[0.4 \mathrm{M}$ Tris (pH 7.5)]. The slides were stained with SYBR-Gold dye (Invitrogen), comets were viewed under an epifluorescent microscope (Zeiss), and the image information was collected using a Comet Assay IV system (Perceptive Instruments).

Statistical analysis was performed for tail intensity data using SPSS software (IBM). The data were collected from three replicate Petri plates, at 2 slides per plate, and 50 cells were examined on each slide, avoiding those located near the edges. A preliminary examination showed that the data were not normally distributed and could not be normalized through logarithmic transformation. Therefore, we applied non-parametric methods for hypothesis testing. Kruskal-Wallis one-way analysis of variance by ranks was used to compare the data distribution for samples at a specific point in time. Following the Kruskall-Wallis test, each of the treatment groups was compared to the control group using a Mann-Whitney U test.

Immunofluorescence. For immunocytochemical analysis, the cells were grown on Lab-Tek chambered 2-well slides (Nulge Nunc International Corp., Naperville, IL) and irradiated. After irradiation, the cells were fixed in $4 \%$ paraformaldehyde in PBS, permeabilized with $70 \%$ ethanol and washed in PBS containing
$0.1 \%$ Triton X-100. Blocking was done in $8 \%$ BSA in PBS. For immunocytochemical detection, the cells were incubated for $2 \mathrm{~h}$ at room temperature using the following antibodies: anti- $\gamma \mathrm{H} 2 \mathrm{AX}$ (Ser 139) rabbit antibodies (1:100, Cell Signaling Technology Inc.), anti-RAD51 rabbit antibodies, anti-pATM and anti-KU70 mouse antibodies (1:100, Santa Cruz Biotechnology Inc.). Afterward, the cells were rinsed and incubated in 1:500 diluted secondary antibodies (goat anti-rabbit IgG Alexa Fluor 488, goat anti-mouse IgG Alexa Fluor 546, and goat anti-mouse IgG Alexa Fluor 488, Invitrogen Molecular Probes, Eugene, OR). Cell nuclei were counterstained with $0.1 \mathrm{mg} / \mathrm{ml}$ 4',6-diamidino2-phenylindole dihydrochloride (DAPI) (Sigma-Aldrich Chemical Co.). The slides were mounted with an anti-fade fluorescence medium prepared from 1,4-diazabicyclo[2.2.2]octane (DABCO), polyvinyl alcohol and glycerol, and analyzed using a Zeiss epifluorescent microscope.

The number of $\gamma \mathrm{H} 2 \mathrm{AX}$ foci per cell was counted in at least 400 cells from each cell group, as previously described (40). The $\gamma \mathrm{H} 2 \mathrm{AX}$ levels are presented as the mean $\pm \mathrm{SE} ; \mathrm{p} \leq 0.05$. The expression levels of pATM, Ku70, and Rad51 were evaluated using the fluorescence intensity of the corresponding antibody. The fluorescence intensity in each cell was measured using CellProfiler cell image analysis software $(41,42)$.

The process used for the analysis is as follows: i) load images; ii) measure image intensity; iii) identify primer automatically; iv) measure object intensity; and v) export to excel. The intensity was represented in intensity units or arbitrary units as mean $\pm \mathrm{SD} ; \mathrm{p} \leq 0.05$.

Statistical analysis. Statistical analysis was performed using MS Excel 2007 and JMP5 software packages.

\section{Results}

Effect of radiation on whole genome gene expression in MCF-7 and MCF-7/DOX cells. Isolated RNA from MCF-7 and MCF-7/DOX cell lines $(17,32)$ was used for gene expression profiling. The background level of gene expression was extremely different in the MCF-7 and MCF-7/DOX cells. In fact, most of the reported housekeeping genes were expressed less in drug-resistant cells than in wild-type parental cells (Fig. 1A). With the help of the DAVID functional annotation array analysis tools, we were able to identify and group the evaluated genes according to their function and possible role in certain pathways. Subsequently, the genes with a similar or identical function were grouped together, and based on their expression changes, the role of certain pathways was evaluated and compared between the two cell lines (Fig. 1B). Fig. 1 demonstrates the identified biological functions and their predominance or weakness in MCF-7/DOX compared to MCF-7. MCF-7/DOX cells had a higher expression of the $\mathrm{ABC}$ transporter genes, which when translated, play a role in pumping the cytotoxic drugs out of the cells, contributing to drug resistance. Similarly, a higher expression of the genes corresponding to cell cycle progression, endocytosis, lysosome, proteolysis, transcription factors, genes contributing to the cancer pathways and drug resistance were found in doxorubicin-resistant cells (Fig. 1B). The genetic profiling of MCF-7/DOX cells also showed an increase in metabolism, immune response and some cell-signaling pathways, such as the MAPK signaling pathway. The primary 


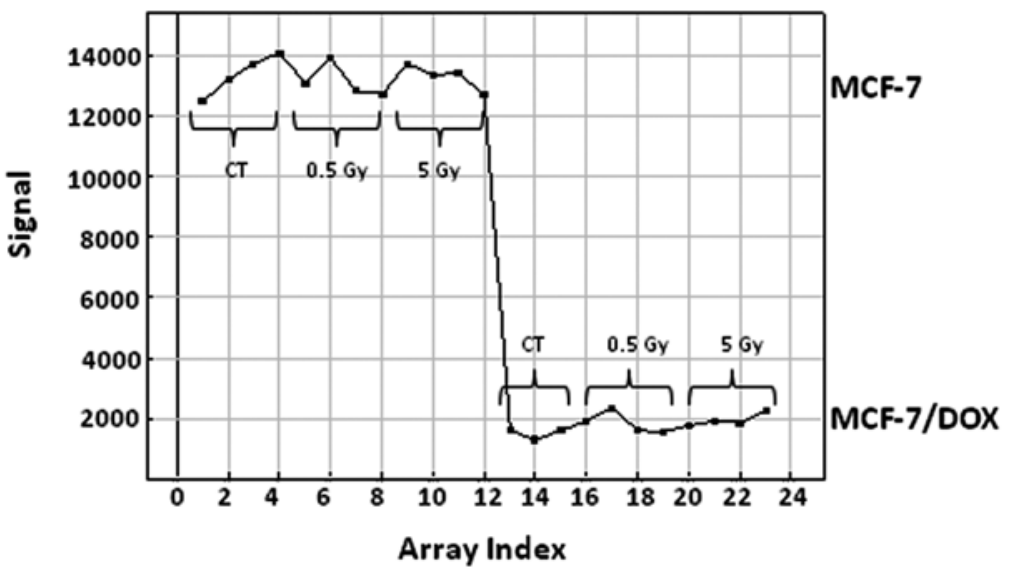

$\begin{array}{lc}\text { Pathways } & \text { \# Genes } \\ \text { ABCtransporters + } & 4 \\ \text { BER - } & 4 \\ \text { Cell cycle + } & 3 \\ \text { Drug re sistance + } & 6 \\ \text { Endocytosis + } & 12 \\ \text { Immune response + } & 47 \\ \text { Lysosome + } & 6 \\ \text { MAPK + } & 22 \\ \text { Metabolism + } & 18 \\ \text { MMR - } & 2 \\ \text { Oxidative phosphorylation - } & 11 \\ \text { Pathways in cancer + } & 12 \\ \text { Proteolysis + } & 7 \\ \text { RNA degradation - } & 3 \\ \text { Rybosome - } & 18 \\ \text { Splicosome - } & 21 \\ \text { Transcription factors + } & 6\end{array}$

$\begin{array}{lc}\text { Pathway } & \text { Genes } \\ \text { Base excision repair } \downarrow & 9 \\ \text { Cell cycle } \downarrow & 32 \\ \text { DNA replication } \downarrow & 23 \\ \text { Homologous recombination } \downarrow & 8 \\ \text { Mismatch repair } \downarrow & 11 \\ \text { Nucle otide excision repair } \downarrow & 13 \\ \text { p53 signaling pathway } \uparrow & 13\end{array}$

Figure 1. Gene expression profiling of MCF-7 and MCF-7/DOX. (A) The expression level of the report housekeeping gene pools in MCF-7 and MCF-7/DOX. The basal expression level (CT) and expression level $24 \mathrm{~h}$ after 0.5 and $5 \mathrm{~Gy}$ of X-ray application is shown. (B) Basal gene expression profiling of the MCF-7/DOX cells. Upregulated (+) and downregulated (-) genes are shown as compared to the MCF-7 cells. All genes were analyzed by DAVID Functional Annotation Array Analysis Database and arranged into pathway groups according to their primary function. (C) X-ray induced gene expression profiling changes in MCF-7 cells $24 \mathrm{~h}$ after 5 Gy exposure. All genes were analyzed by DAVID Functional Annotation Array Analysis Database and arranged into pathway groups according to their primary function. Pathway activation $(\uparrow)$ or inhibition $(\downarrow)$ is shown for the treated cells when compared with untreated controls.

downregulated processes in MCF-7/DOX cells in comparison to the MCF-7 parental line were: oxidative phosphorylation, ribosome and RNA degradation and splicing (Fig. 1B).

It is possible that the previously mentioned difference in the genetic profiling of MCF-7/DOX cells could affect the response of these cells to radiation treatment. Neither low (0.5 Gy) nor high (5 Gy) X-ray doses caused any changes in the gene expression of MCF-7/DOX. In contrast, MCF-7 cells showed an extreme genetic response to the high (5 Gy) X-ray dose (Fig. 1C). Thirty-two cell cycle genes and 23 genes responsible for DNA replication were downregulated (Fig. 1C). The primary repair processes were shut down by the decreased expression of key genes. Parental cells lost their MMR, NER, BER and HR due to the downregulation of the $11,13,9$ and 8 pathway genes, respectively (Fig. 1C). These changes usually lead to cell death. Moreover, the genes responsible for cell death from the p53 signaling pathway were upregulated (Fig. 1C).

The validity of gene expression profiling was confirmed by qRT-PCR for the genes with the most change and the greatest radiation response. Therefore, the primary targets for qRT-PCR were: DNA polymerases $\mathrm{A}, \mathrm{D}$ and $\mathrm{E}$, which are the key components in DNA replication and DNA repair pathways, and cyclin A, GADD45G, and aurora B, which play an important role in cell cycle and p53 signaling pathways.
Aurora B is a protein kinase that functions through the attachment of the mitotic spindle to the centromere and provides equal chromosome movement and segregation during mitosis. The level of $A U R K B$ transcripts gradually and significantly decreased in the MCF-7 parental line after X-ray treatment (Table I). There was no change in AURKB expression found in MCF-7/DOX cells after irradiation and the background expression level was significantly lower in the drug-resistant cell line than the parental cells. Similar to $A U R K B$, cyclin A $(C C N A)$ was downregulated in parental cells after X-ray exposure (Table I). Because cyclin $\mathrm{A}$ binds to $\mathrm{S}$ phase $\mathrm{Cdk} 2$ and is required for the cell to progress through the $\mathrm{S}$ phase, the deficit of cyclin A may contribute to cell cycle arrest. There was no change in cyclin A expression found in MCF-7/DOX cells, and the background level of the cyclin A expression was significantly lower in the cells resistant to doxorubicin.

GADD45G is a growth arrest and DNA-damage-inducible protein whose levels are increased following stressful growth arrest conditions and treatment with DNA-damaging agents. The protein encoded with $G A D D 45 G$ responds to environmental stresses by mediating the activation of the $\mathrm{p} 38$ / JNK pathway. Both 0.5 and 5 Gy X-rays caused an increase in $G A D D 45 G$ transcript levels in MCF-7 cells, which is in contrast to levels in MCF-7/DOX cells (Table I). Interestingly, 
Table I. Fold change (corrected for internal standard) in levels of gene transcripts of aurora B, cyclin A, Gad45G and polymerases A, $\mathrm{D}$ and $\mathrm{E}$ detected by qRT-PCR.

\begin{tabular}{|c|c|c|c|c|c|c|c|c|}
\hline \multirow[b]{2}{*}{ Gene } & \multicolumn{3}{|c|}{ PT } & \multicolumn{3}{|c|}{ DOX } & \multicolumn{2}{|c|}{$\mathrm{CT}$} \\
\hline & $\mathrm{CT}$ & 0.5 & 5 & $\mathrm{CT}$ & 0.5 & 5 & PT & DOX \\
\hline \multicolumn{9}{|l|}{ Aurora B } \\
\hline $\begin{array}{l}\text { Relative fold change } \\
\text { P-value }\end{array}$ & 1 & $\begin{array}{l}0.9 \\
0.01\end{array}$ & $\begin{array}{l}0.8 \\
0.00\end{array}$ & 1 & $\begin{array}{l}1.1 \\
0.09\end{array}$ & $\begin{array}{l}1.1 \\
0.10\end{array}$ & 1 & $\begin{array}{l}0.2 \\
0.00\end{array}$ \\
\hline \multicolumn{9}{|l|}{ Cyclin A } \\
\hline $\begin{array}{l}\text { Relative fold change } \\
\text { P-value }\end{array}$ & 1 & $\begin{array}{l}1 \\
0.21\end{array}$ & $\begin{array}{l}0.9 \\
0.00\end{array}$ & 1 & $\begin{array}{l}0.9 \\
0.09\end{array}$ & $\begin{array}{l}1 \\
0.28\end{array}$ & 1 & $\begin{array}{l}0.2 \\
0.00\end{array}$ \\
\hline \multicolumn{9}{|l|}{ Gad45G } \\
\hline $\begin{array}{l}\text { Relative fold change } \\
\text { P-value }\end{array}$ & 1 & $\begin{array}{l}2.1 \\
0.00\end{array}$ & $\begin{array}{l}2 \\
0.02\end{array}$ & 1 & $\begin{array}{l}1.2 \\
0.81\end{array}$ & $\begin{array}{l}1.1 \\
0.83\end{array}$ & 1 & $\begin{array}{l}5.7 \\
0.00\end{array}$ \\
\hline \multicolumn{9}{|l|}{ PolA } \\
\hline $\begin{array}{l}\text { Relative fold change } \\
\text { P-value }\end{array}$ & 1 & $\begin{array}{l}0.8 \\
0.22\end{array}$ & $\begin{array}{l}0.3 \\
0.00\end{array}$ & - & - & - & 1 & 0 \\
\hline \multicolumn{9}{|l|}{ PolD } \\
\hline $\begin{array}{l}\text { Relative fold change } \\
\text { P-value }\end{array}$ & 1 & $\begin{array}{l}1 \\
0.09\end{array}$ & $\begin{array}{l}0.9 \\
0.00\end{array}$ & - & - & - & 1 & 0 \\
\hline \multicolumn{9}{|l|}{ PolE } \\
\hline $\begin{array}{l}\text { Relative fold change } \\
\text { P-value }\end{array}$ & 1 & $\begin{array}{l}1 \\
0.07\end{array}$ & $\begin{array}{l}0.8 \\
0.00\end{array}$ & 1 & $\begin{array}{l}1 \\
0.71\end{array}$ & $\begin{array}{l}1 \\
0.48\end{array}$ & 1 & $\begin{array}{l}0.3 \\
0.00\end{array}$ \\
\hline
\end{tabular}

Each treatment group was compared to its corresponding control. 18SrRNA was used as a reference gene (calculated by Pfaffl). P-values calculated by Student's t-test.

the background expression level of $G A D D 45 G$ was higher in drug-resistant cells, which could be due to the genomic instability in cells that acquired drug resistance. All three polymerases (A, D and E) were significantly downregulated in response to a 5 Gy radiation treatment in their parental cell lines (Table I), disabling the polymerization of deoxyribonucleotides into a DNA strand. There were no changes in the expression level of the three polymerases found in MCF-7/DOX cells; moreover, the control expression level of polymerases was so low that POLD and POLA could not be identified using qRT-PCR.

Levels of DNA polymerase proteins in MCF-7 and $M C F-7 / D O X$ cells. Taking the results into consideration, we wondered how drug-resistant cells survived radiation, how they proliferated and what DNA polymerases they used for replication and DNA repair. We, therefore, analyzed the protein levels of polymerases $\delta, \varepsilon, \beta$, and $\iota$ in the MCF-7 and MCF-7/DOX cells.

The expression level of both polymerases $\delta$ and $\varepsilon$ were found to be higher in MCF-7 cells, similar to gene expression profiling analysis and qRT-PCR analysis (Fig. 2). Furthermore, the level of DNA polymerase $\delta$ was slightly increased in doxorubicin-resistant MCF-7/DOX cells after radiation exposure.

Two other polymerases ( $\beta$ and $\iota$ ) were highly expressed in MCF-7/DOX. While the polymerase $\beta$ level was much lower in MCF-7 cells than in MCF-7/DOX, polymerase । was not detected in the parental cells at all (Fig. 2). DNA polymerase $\iota$ was recently discovered as a polymerase that catalyses error-prone DNA synthesis. It promotes the replication of damaged DNA by misincorporating deoxynucleotides opposite DNA lesions $(43,44)$. We doubted whether the high expression of polymerase $\iota$ provided a fast, yet inaccurate, DNA repair in DOX cells following any DNA-damaging treatment, including X-ray exposure.

Analysis of the fidelity of DNA polymerases in MCF-7 and $M C F-7 / D O X$ cells. All types of DNA repair involve the resynthesis of DNA to replace damaged strands. To uncover any correlation between the dynamics of the induction and repair of IR-induced DNA damage, we studied the fidelity of the DNA polymerase pool in the cell lysates from MCF-7 and MCF-7/DOX (Fig. 3). Because doxorubicin-resistant MCF-7/DOX cells managed to survive DNA damage, we hypothesized that low fidelity DNA polymerases may be more active in the resistant cells. Therefore, we analyzed the DNA polymerase fidelity in MCF-7 and MCF-7/DOX (37).

DNTPs were added to the mixture containing the template and extracts of the unirradiated or irradiated MCF-7 or MCF-7/DOX cells and the incorporation patterns were analyzed. According to the template sequence, the next nucleotide to be inserted was dGTP. When only dGTP was in the reaction mixture, we obtained a 16-bp gel band with a higher intensity in MCF-7/DOX; moreover, the band corresponding to the irradiated MCF-7/DOX had the 

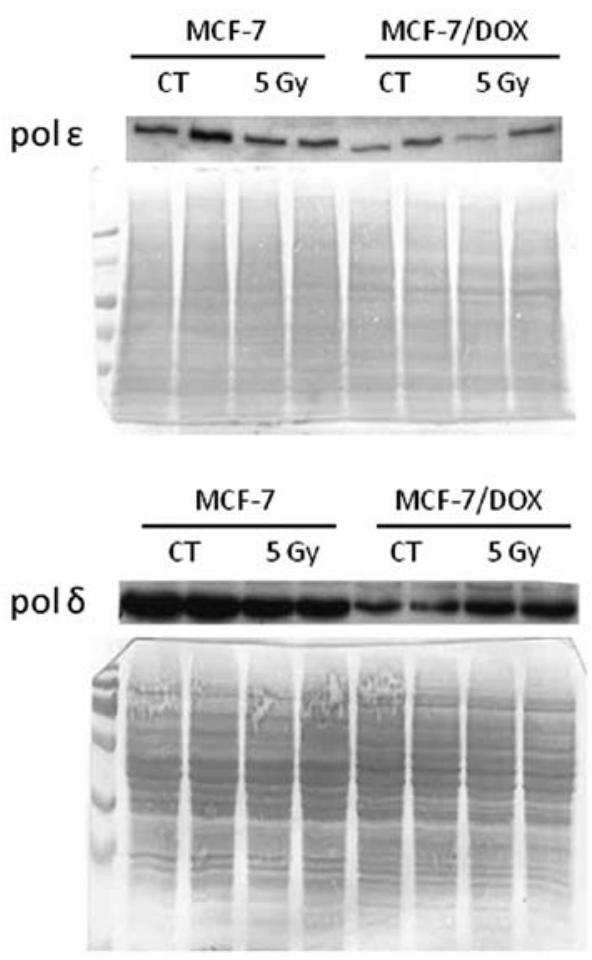
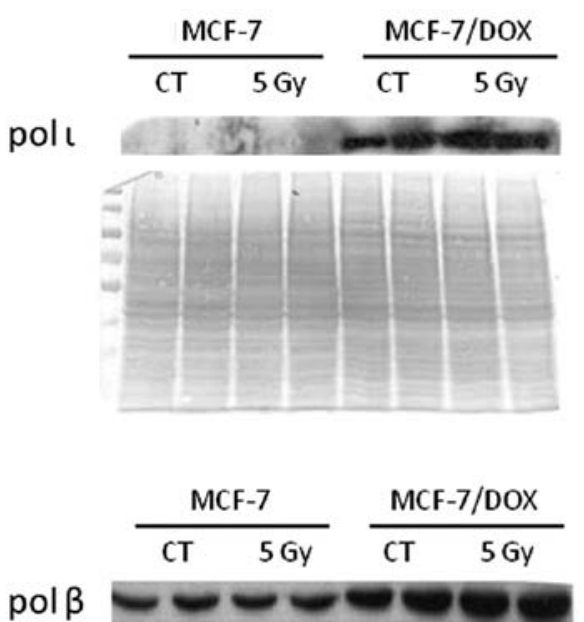

pol $\beta$

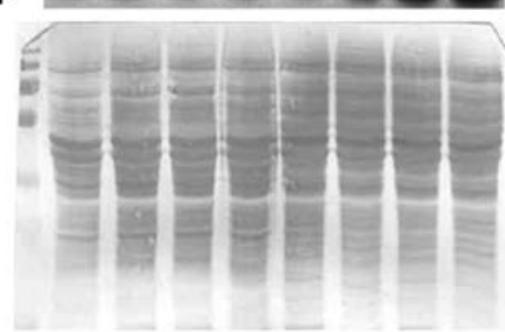

Figure 2. Expression of DNA polymerases $\delta, \beta, \varepsilon$ and $\iota$ in MCF-7 and MCF-7/DOX cells. Representative blots from 3 independent experiments are shown. PVDF membranes were stained with Coomassie Brilliant Blue G-250 to confirm an equal amount of loaded sample.

highest intensity (Fig. 3A). The observed difference may be explained by higher DNA polymerase activity or an increased amount of polymerases in resistant cells. The latter idea would make sense only for certain polymerases, such as polymerases $\beta$ or $\mathrm{\iota}$; as polymerases $\alpha, \varepsilon$ and $\delta$ were previously shown to be downregulated in MCF-7/DOX.

Furthermore, as shown in Fig. 3B, MCF-7/DOX had a higher level of dATP misincorporation, which means that DNA polymerase specificity or fidelity is lower in the drugresistant cells. We did not observe the incorporation of dTTP and dCTP. Therefore, we concluded that ATP is the most common incorrect nucleotide to be inserted by the low fidelity polymerases to continue synthesis in MCF-7/DOX cells.

When adding both dGTPs and dATPs or all dNTPs to the samples, we obtained 16 and 17 bp bands and completed synthesis, respectively (Fig. 3D). In all the cases, the activity of the polymerases was higher in the MCF-7/DOX-resistant cell line. At the same time, we observed more intense DNA cleavage in MCF-7 cells due to significant exonuclease activity. The excision of incorrect nucleotides by exonucleases reduces mismatches. The control sample did not contain any dNTPs, and no band with a weight higher than $15 \mathrm{bp}$ was observed (Fig. 3C). The negative control contained all the dNTPs and EDTA (to inactivate all metal-using enzymes). Under these conditions, the exonuclease activity was lower and the intensity of all the bands was the same (Fig. 3E). Both controls indicated that there were no endogenous oligonucleotides observed in the gels (Fig. 3). In summary, we concluded that irradiated and non-irradiated MCF-7/DOX cells exhibited significantly higher processivity and significantly lower polymerases fidelity.
Radiation-induced apoptosis in MCF-7 breast adenocarcinoma cells and their drug-resistant counterpart, MCF-7/DOX cells. In this study, we characterized and compared the responses of the MCF-7 breast adenocarcinoma line and its doxorubicinresistant variant (MCF-7/DOX) to ionizing radiation (IR) in vitro. IR exposure is known to induce apoptotic cell death in irradiated cells. Therefore, we analyzed the levels of IR-induced apoptosis in MCF-7 and MCF-7/DOX cells. Early apoptosis is characterized by various changes in the cellular plasma membrane; the primary change is the translocation of phosphatidylserine (PS) from the inner layer to the surface of the membrane. Annexin V possesses a high affinity to PS, and this allows for the early detection of apoptotic changes (45). Here, we analyzed IR-induced apoptosis using the Annexin V assay.

Fig. 4 shows that MCF-7 cells began to undergo early apoptosis $24 \mathrm{~h}$ after irradiation. We found a 1.67 and 1.75 -fold increase in Annexin V positive cells $24 \mathrm{~h}$ after exposure to 0.5 and 5 Gy X-rays, respectively. The percentage of MCF-7 cells in early apoptosis returned to the control level within $48 \mathrm{~h}$ (Fig. 4); however, the number of dead cells increased at this time point. These changes may indicate that cells that were undergoing early apoptosis $24 \mathrm{~h}$ after irradiation were dead within $48 \mathrm{~h}$. In contrast, MCF-7/DOX-resistant cells only showed an apoptotic response $48 \mathrm{~h}$ after treatment with the high IR dose ( $5 \mathrm{~Gy}$ ). The 2.87-fold increase in Annexin V positive cells was reached $48 \mathrm{~h}$ after the X-ray treatment of MCF-7/DOX cells (Fig. 4). Based on these data, we concluded that MCF-7/DOX cells exhibit a significantly delayed apoptotic response to ionizing radiation.

Radiation-induced DNA damage in MCF-7 and MCF-7/DOX cells. Next, we analyzed the structures associated with such significant differences in IR-induced apoptotic responses in the 
A

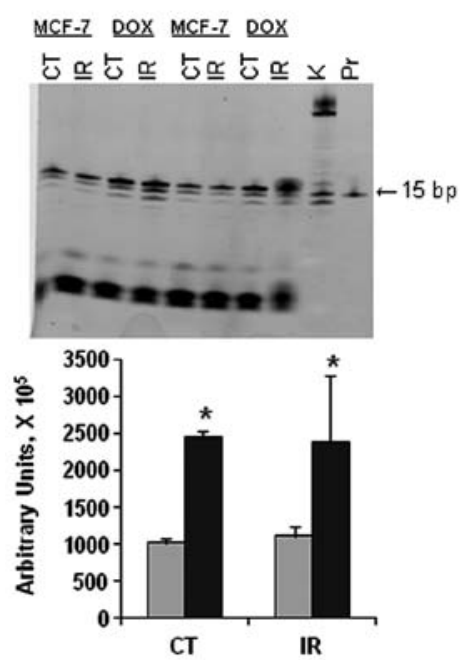

B

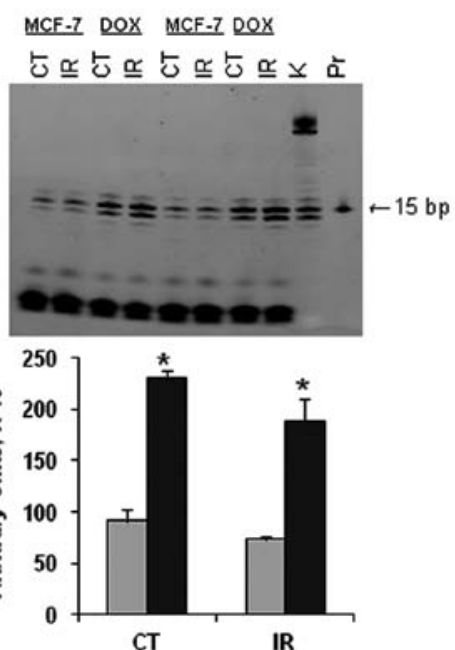

C no dNTP

MCF-7 DOX MCF-7DOX

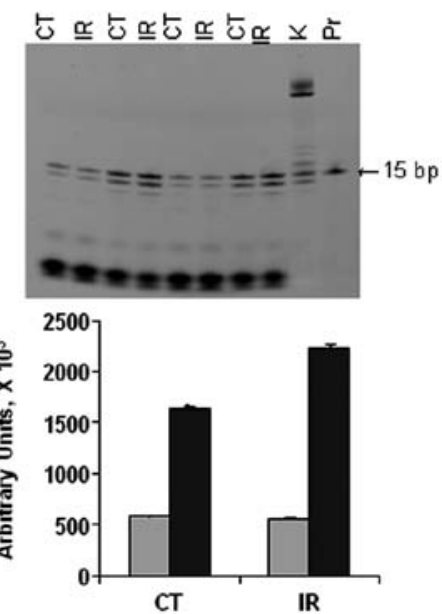

D dNTPS

MCF-7 DOX MCF-7DOX

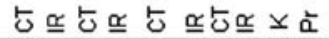

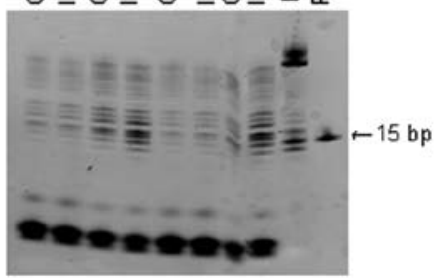

E dNTPs+50 mM EDTA

MCF-7 DOX MCF-7 DOX

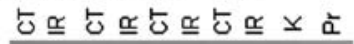

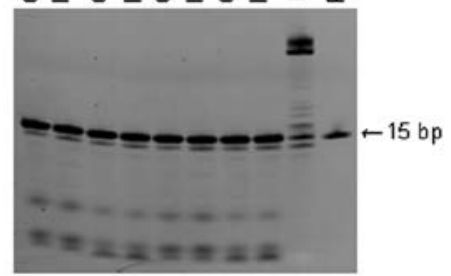

Figure 3. DNA polymerase fidelity in MCF-7 and MCF-7/DOX cells. (A) DNA polymerase procesivity measured by intensity of the 16 bp dGTP bands. (B) DNA polymerase fidelity measured by intensity of the $16 \mathrm{bp}$ dATP bands. (C) DNA exonuclease procesivity measured by intensity of the 15 bp bands when no dNTPs addded. Less intensity of bands corresponds to higher exonuclease procesivity. (D) Completed DNA synthesis when all the dNTPs added. (E) No DNA synthesis when all dNTPs added in the presence of $50 \mathrm{mM}$ EDTA that blocks all metal-dependent enzymes. For all figures: K, Klenow enzyme, a positive control; Pr, primer only, 4 pmol; CT, control; IR, irradiated. Cell extracts were loaded in double repeats. Intensity of bands was measured using ImageQuant 5.2 software program (Molecular Dynamics). Grey bars on the figures, MCF-7; black bars, MCF-7/DOX. " p $<0.5$, significantly different from correspondent MCF-7.
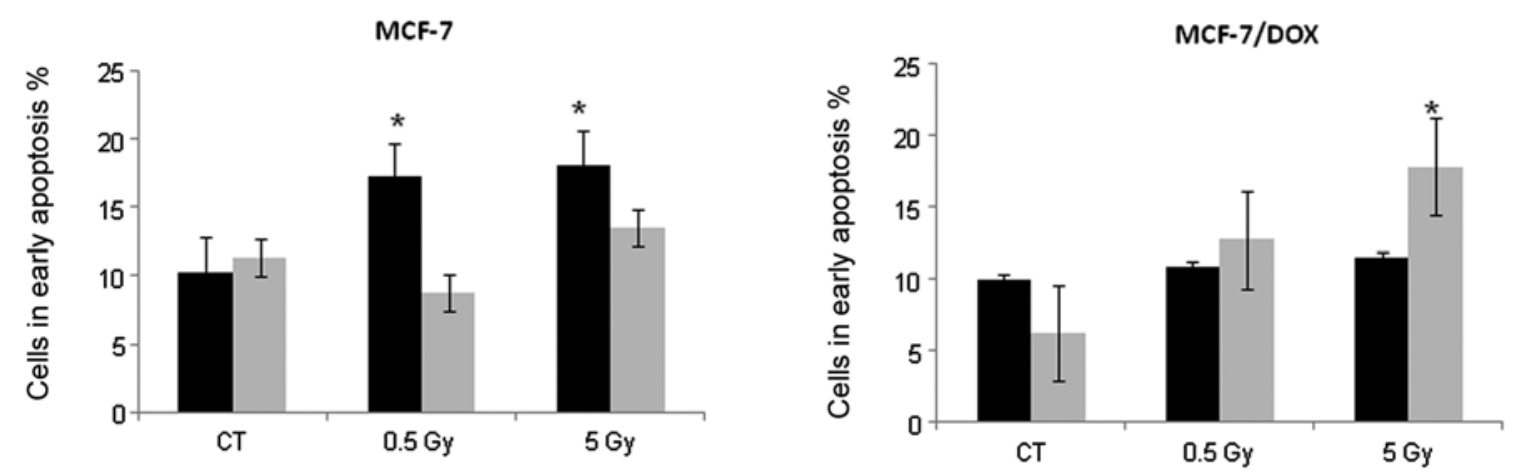

Figure 4. Radiation-induced apoptosis in MCF-7 and MCF-7/DOX cells. The number of cells in early apoptosis was measured using Annexin V-FITC assay for control cells (CT) and cells irradiated with 0.5 and $5 \mathrm{~Gy}$ of $\mathrm{X}$-rays. The results are presented as mean values $\pm \mathrm{SEM}, \mathrm{n}=6$. ${ }^{*} \mathrm{p}<0.05$, significantly different from respective control, Student's t-test. Black bars, $24 \mathrm{~h}$ after exposure and grey bars, $48 \mathrm{~h}$ after exposure.

MCF-7 and MCF-7/DOX cells. IR is a potent DNA-damaging agent capable of inducing cross linking, nucleotide base damage, and most importantly, single and double strand breaks (DSBs), which are well-known inducers of apoptosis $(46,47)$. Therefore, we analyzed and compared the levels of IR-induced DNA damage in MCF-7 and MCF-7/DOX cells using the Comet assay and by detecting $\gamma \mathrm{H} 2 \mathrm{AX}$ foci, a well accepted indicator of DNA double-strand breaks (48).

In the comet assay, the super coiled duplex DNA underwent unwinding and denaturation under strong alkaline condi- 

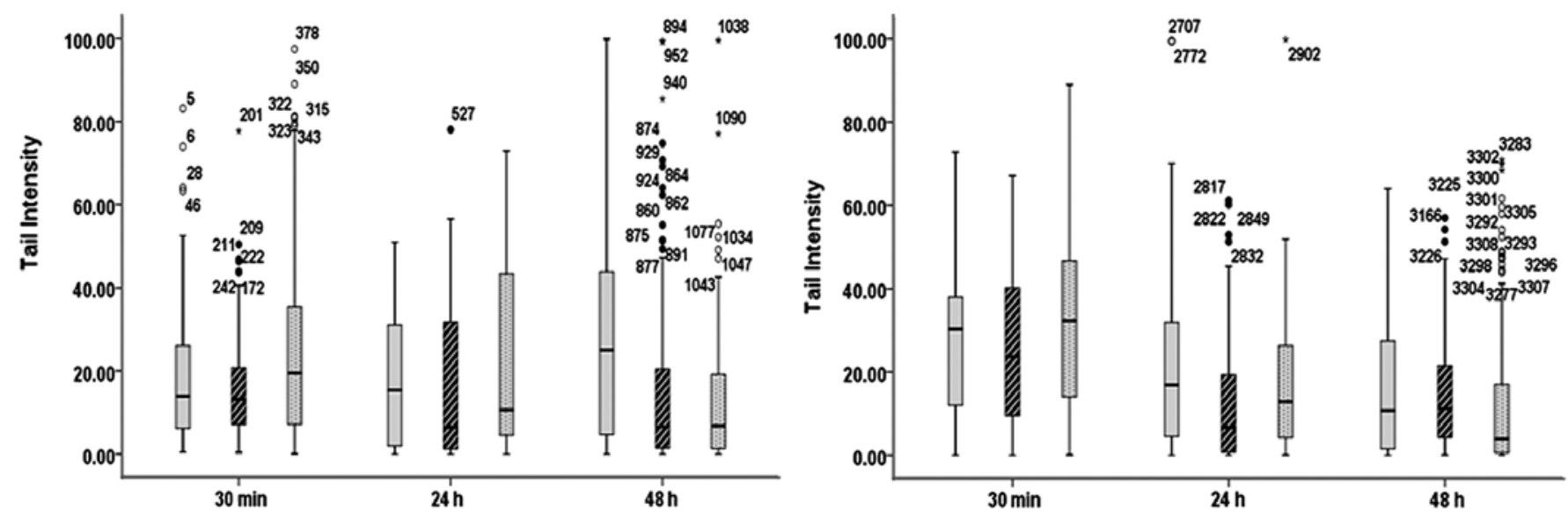

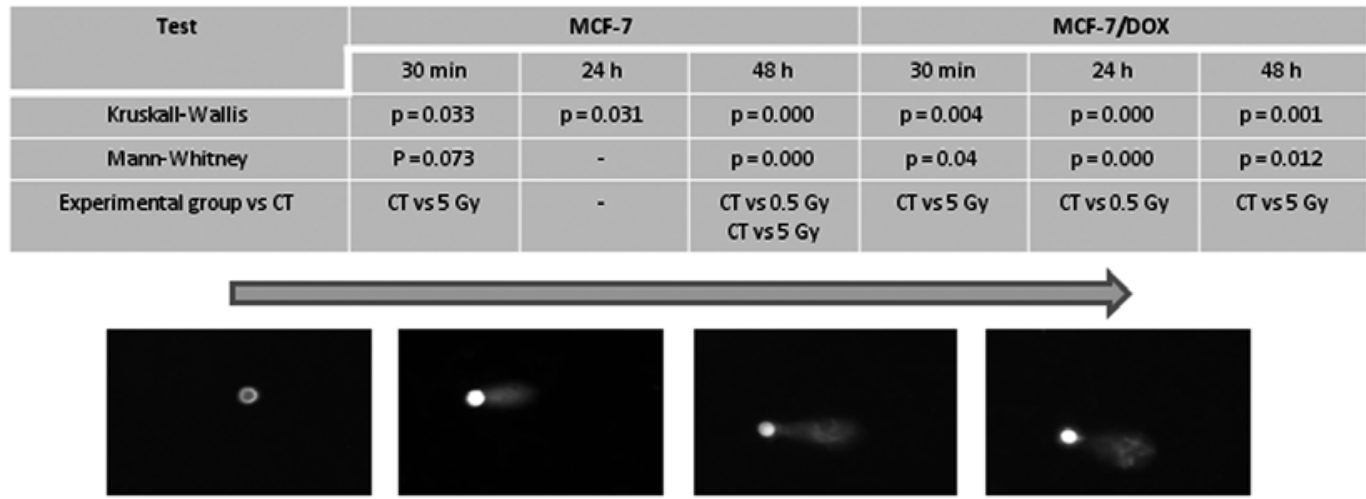

Figure 5. Radiation-induced DNA damage in MCF-7 and MCF-7/DOX cells as determined by the Alkaline Comet assay. The graph represents percent of DNA in the comet tails (tail intensity) obtained by the Alkaline Comet assay performed on MCF-7 and MCF-7/DOX cells 30 min, 24 and $48 \mathrm{~h}$ after X-ray irradiation. Box-and-whisker plot represents a range, interquartile distance and a median. Extreme values were plotted as separate datapoints. No fill bars, CT; angular bars, $0.5 \mathrm{~Gy}$; and dotted bars, $5 \mathrm{~Gy}$. Kruskal-Wallis one-way analysis of variance by ranks was used to compare data distribution for samples within a time-point. Following Kruskall-Wallis test each of the treatment groups was compared to the control group using Mann-Whitney U test. Comet representitve pictures of tail intensity are located below the charts.

tions (49). This led to DNA fragment size reductions and the expression of alkali labile sites as single-strand breaks, which are stretched out by electrophoresis. A comet tail consisting of the damaged or broken DNA fragments was analyzed through the intensity in both types of MCF-7 cells after radiation treatment (Fig. 5). A 5 Gy X-ray led to significant damage in MCF-7 parental and drug-resistant cells immediately (30 min) after application. The damage is believed to represent DSBs, SSBs, alkali labile sites and breaks from replication events. The persistence of the damage was only observed for up to $24 \mathrm{~h}$ in the parental line, and no significant damages were observed in the drug-resistant line after 24-48 h (Fig. 5).

Similarly, both 0.5 and 5 Gy X-ray doses led to the formation of $\gamma \mathrm{H} 2 \mathrm{AX}$ foci in MCF-7 and MCF-7/DOX cells. However, MCF-7/DOX cells were much less sensitive to IR than MCF-7 cells (Fig. 6). Specifically, the irradiation of MCF-7 cells caused significant (2.6 and 8.5 times) increases in the levels of $\gamma \mathrm{H} 2 \mathrm{AX}$ foci, from $3.14 \pm 0.22$ foci per cell in the control to $8.23 \pm 0.53$ and $26.70 \pm 1.02$ foci per cells $30 \mathrm{~min}$ after 0.5 and $5 \mathrm{~Gy}$ treatments, respectively (Fig. 6A). The $\gamma \mathrm{H} 2 \mathrm{AX}$ foci induced by $0.5 \mathrm{~Gy}$
X-rays disappeared $48 \mathrm{~h}$ after irradiation, indicating efficient DNA repair. The application of $5 \mathrm{~Gy} \mathrm{X}$-rays led to the persistent elevation of $\gamma \mathrm{H} 2 \mathrm{AX}$ foci, as detected $48 \mathrm{~h}$ after exposure.

In MCF-7/DOX cells, radiation exposure led to significant (1.9 and 6.0 times) increases in the levels of $\gamma \mathrm{H} 2 \mathrm{AX}$ foci, from $1.83 \pm 0.2$ foci per cell in the control to $3.49 \pm 0.15$ and $10.9 \pm 0.44$ foci per cell after $0.5 \mathrm{~Gy}$ and $5 \mathrm{~Gy}$ treatments, respectively (Fig. 6B). The levels $\gamma \mathrm{H} 2 \mathrm{AX}$ foci significantly decreased 24 and $48 \mathrm{~h}$ after irradiation.

Most importantly, the levels of $\gamma \mathrm{H} 2 \mathrm{AX}$ foci in all cases in MCF-7 cells were significantly different from the levels seen at the corresponding time-points in MCF-7/DOX cells (Fig. 6). MCF-7/DOX cells exhibited lower levels of IR-induced DNA damage and faster repair of $\gamma \mathrm{H} 2 \mathrm{AX}$ compared to the sensitive MCF-7 cells.

Analysis of the DNA repair machinery in MCF-7 and MCF-7/ DOX cells. The apparent differences in the levels of IR-induced DNA damage between MCF-7 and MCF-7/DOX cells have led us to question how the resistant cells repair the DNA lesions. In 
A
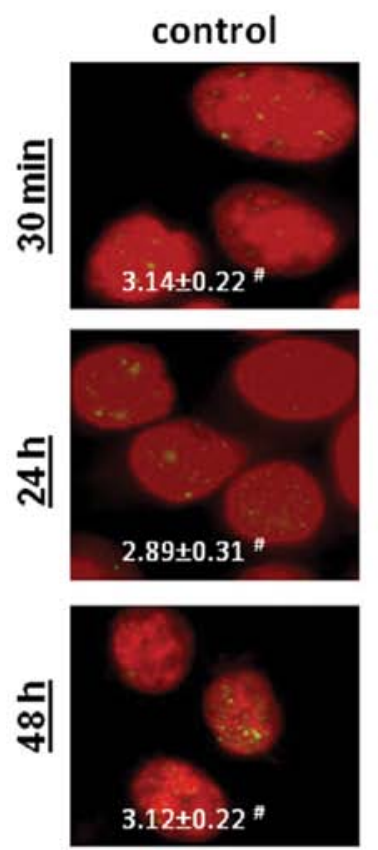

B
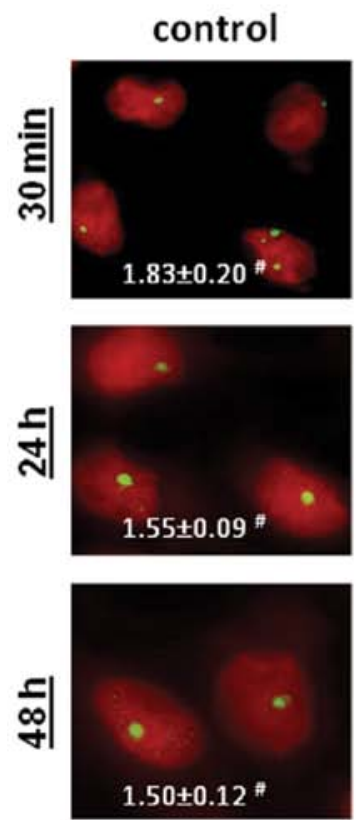

$\underline{\text { MCF-7 }}$
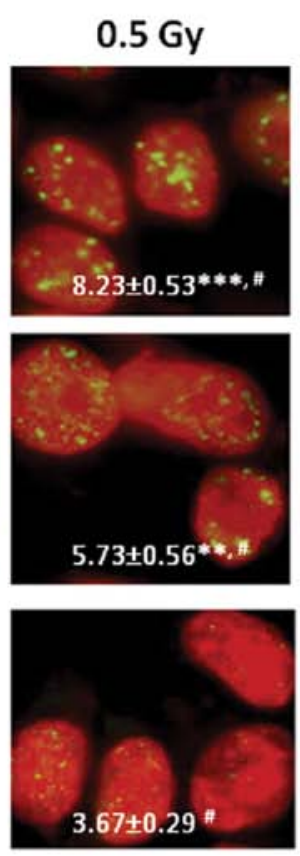

MCF-7IDOX
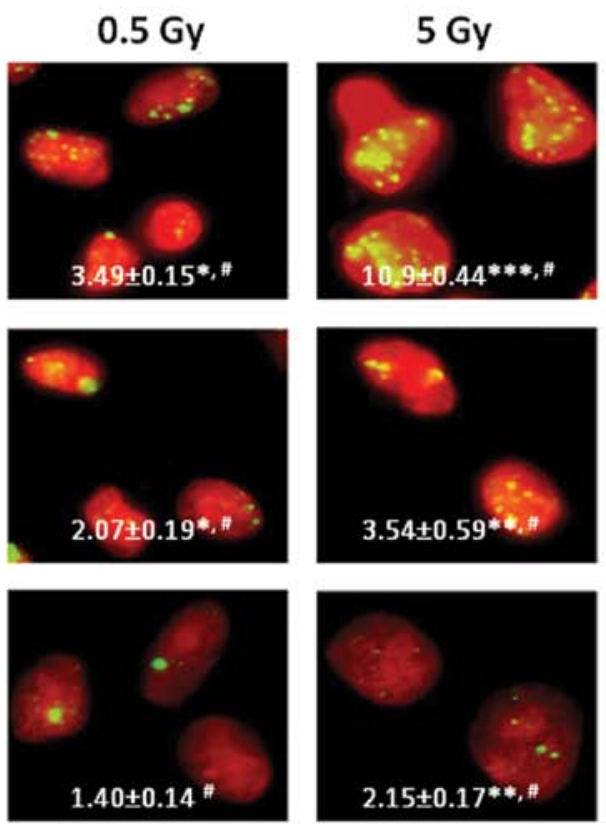
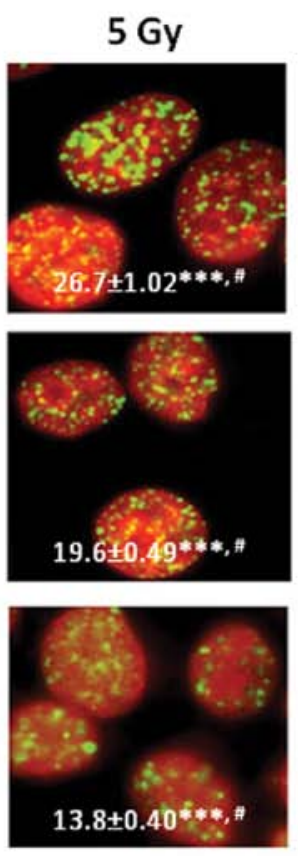

Figure 6. Radiation-induced H2AX phosphorylation in MCF-7 and MCF-7/DOX cells. (A) MCF-7 cells; (B) MCF-7/DOX cells. Results are presented as average number of $\gamma \mathrm{H} 2 \mathrm{AX}$ foci per cell $\pm \mathrm{SE}, \mathrm{n}=200 .{ }^{* *} \mathrm{p}<0.01$, significantly different from the respective control; ${ }^{* * * *} \mathrm{p}<0.001$, significantly different from the respective control; Student's t-test. ${ }^{\#}$ p<0.05, significantly different between the corresponding dose and time-points in two cell lines - MCF-7 and MCF-7/DOX, Student's t-test. Magnification, $\mathrm{x} 100$. Red, DAPI, green, $\gamma \mathrm{H} 2 \mathrm{AX}$.

mammalian cells, two processes exist to repair DSBs: homologous recombination (HR) and non-homologous end-joining (NHEJ) (50-53). The key component for both processes is the serine/threonine specific protein kinase ATM. The phosphorylation of ATM is necessary for DSB repair $(48,54)$. Therefore, we analyzed the level of phosphorylated ATM (pATM) in MCF-7 and MCF-7/DOX cell lines after irradiation.
Overall, the level of pATM was higher in MCF-7/DOX cells. Interestingly, the subcellular localization of the protein was different in MCF-7 and MCF-7/DOX cell lines (Fig. 7A). For example, in MCF-7 cells, pATM was detected as nuclear foci (Fig. 7A). The number of pATM nuclear foci in MCF-7 cells increased after irradiation. The dynamics of PATM expression were similar to that of $\gamma \mathrm{H} 2 \mathrm{AX}$ (Fig. 7A). 
A

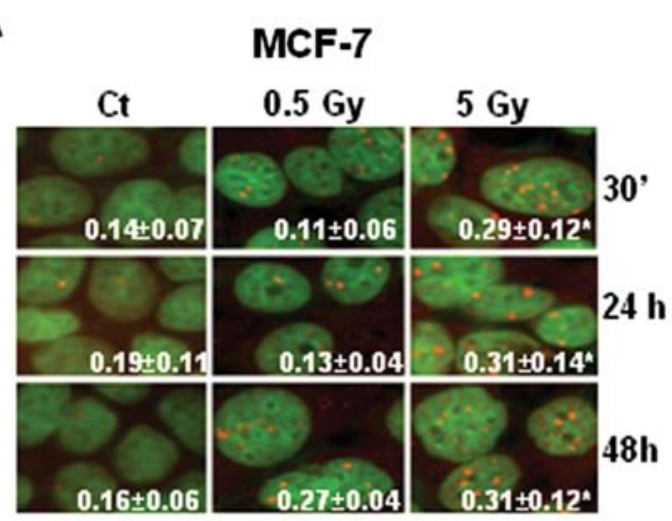

B

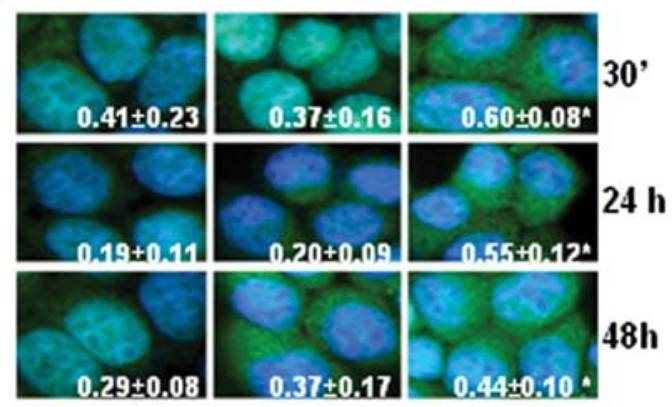

C

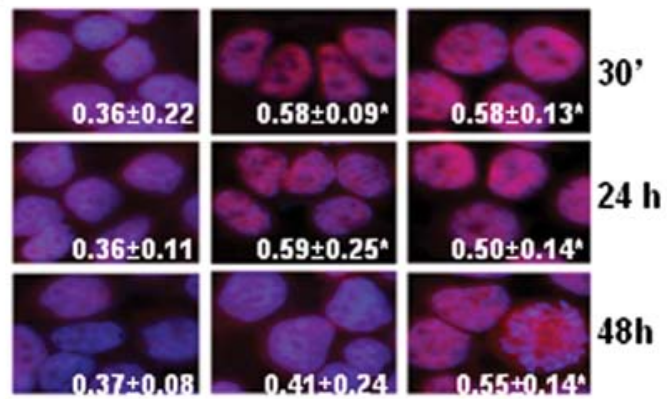

MCF-7IDOX
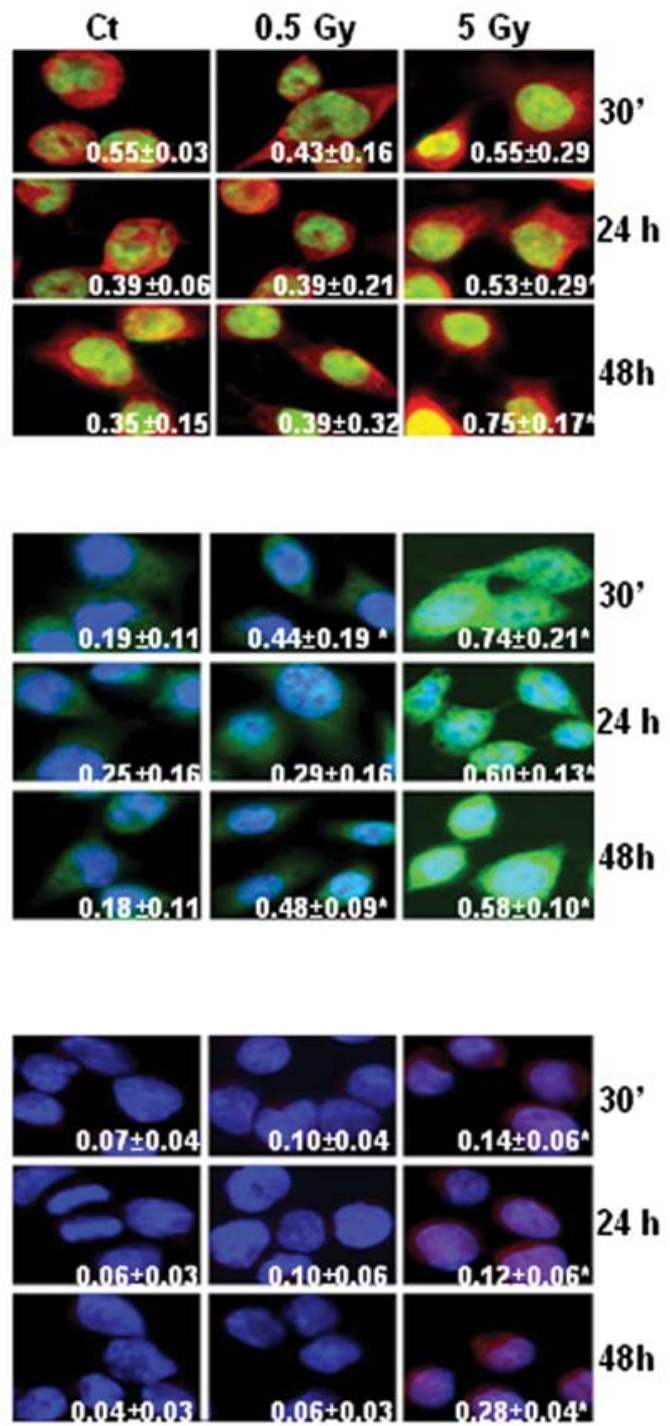

Figure 7. (A) Phospho-ATM, (B) RAD51 and (C) Ku70 levels in MCF-7 and MCF-7/DOX cells before and after radiation exposure. Protein levels are represented as average intensity of protein-specific staining from each cell $\pm \mathrm{SD}$; $\mathrm{p}<0.05$, significantly different from corespondent control; Student's t-test. Magnification, $\mathrm{x} 100$. (A) Green, DAPI; red, p-ATM; (B) blue, DAPI; green, RAD51; and (C) blue, DAPI; red, KU70.

In MCF-7/DOX-resistant cells, slight pATM foci were observed, and the protein was localized in both the nucleus and cytoplasm. Yet, the general level of pATM in MCF-7/DOX cells measured by fluorescent intensity was higher than that in the MCF-7 cells (Fig. 7A). With evidence of different levels of $\gamma \mathrm{H} 2 \mathrm{AX}$ and pATM in MCF-7 and MCF-7/DOX cells, we then asked if HR or NHEJ-related proteins were differentially induced in these cell lines after irradiation. RAD51 is a key protein essential for the repair of DSBs via HR in mammals (55). KU70 is a key participant in the NHEJ pathway that repairs DSBs $(56,57)$.

Immunocytochemistry was performed to analyze the levels of RAD51 and KU70 in MCF-7 and MCF-7/DOX cells after irradiation. We found that the expression level of RAD51 increased after irradiation in both cell lines (Fig. 7B), but the highest level was observed in MCF-7/DOX cells after exposure to 5 Gy X-rays (Fig. 7B).
Interestingly, MCF-7 cells expressed relatively high levels of KU70 prior to irradiation, and an abundant amount of the protein was found after exposure (Fig. 7C). On the contrary, KU70 levels were almost undetectable in non-irradiated MCF-7/DOX cells, and only exposure to 5 Gy X-rays resulted in a noticeable upregulation of KU70 levels (Fig. 7C). Overall, we concluded that MCF-7/DOX cells harbored higher DNA repair potential than sensitive MCF-7 cells.

The immunocytochemistry results for RAD51 and KU70 repair proteins were confirmed using a western immunoblot assay (Fig. 8). High expressions of KU70 in both the control and irradiated MCF-7 cells were observed, but there was an absence of KU70-specific bands in MCF-7/DOX cells. In contrast, RAD51 expression was only found in MCF-7/DOX cells (Fig. 8). This difference in the preference of the two cell lines to different types of DNA DSBs repair may be due to the differences in the proliferative potentials of these cell lines. The 

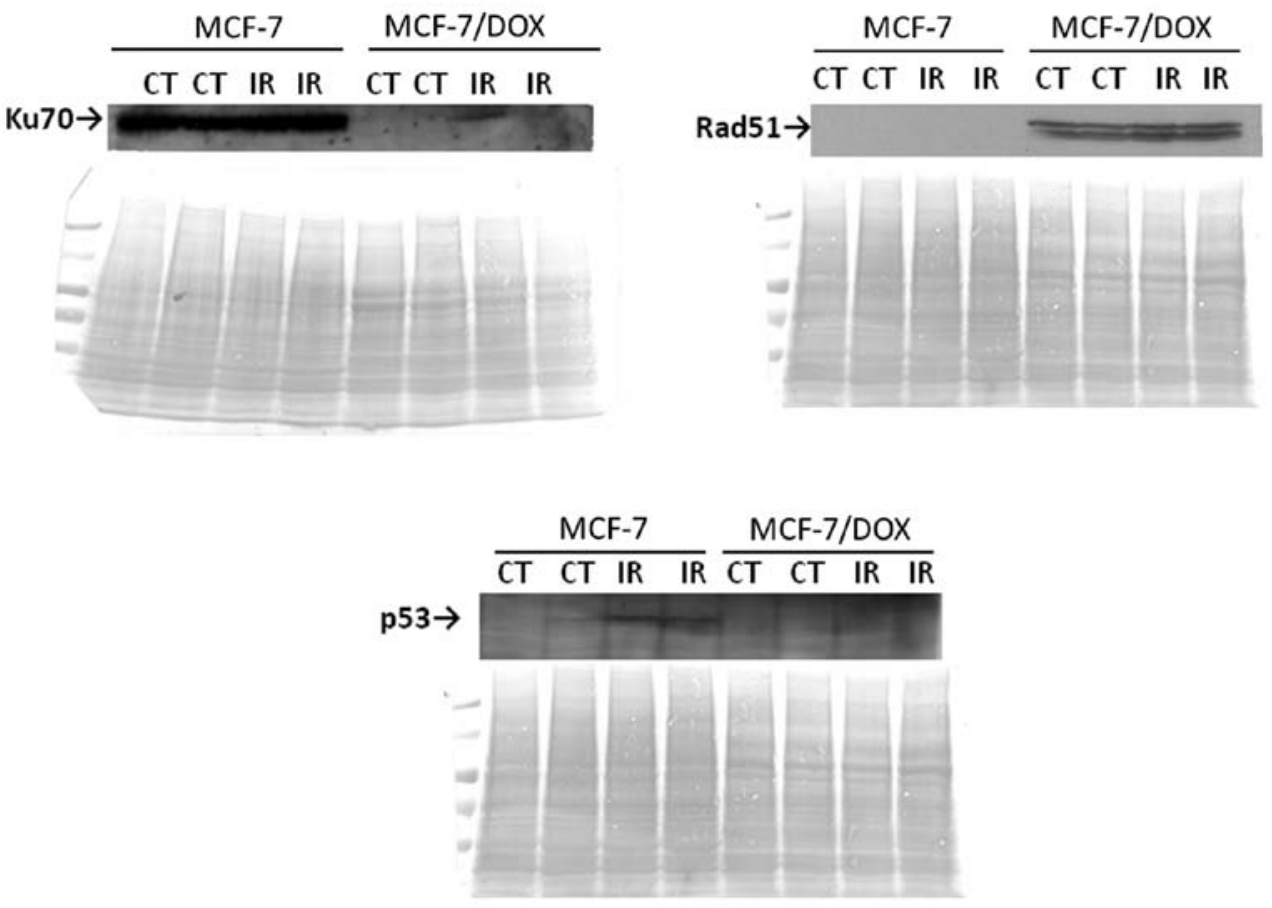

Figure 8. Expression of Ku70, Rad51 and p53 in MCF-7 and MCF-7/DOX cells. Representative blots from 3 independent experiments are shown. PVDF membranes were stained with Coomassie Brilliant Blue G-250 to confirm an equal amount of loaded sample. CT, untreated cells; IR, cells harvested 24 h after irradiation with 5 Gy of X-rays.

highly proliferative MCF-7/DOX cells may use an available sister chromatid for the homology search that is needed for HR.

The p53 protein is a well known DNA damage response initiator that induces long-term checkpoint activation. As expected, a 5 Gy X-ray treatment led to p53 elevation in MCF-7 cells. However, no change in the p53 protein level was observed in the MCF-7/DOX line (Fig. 8).

\section{Discussion}

Relapse risk in breast cancer is largely dependent on the combination of anticancer treatment modalities. Anthracycline chemotherapy is increasingly used for treating locally advanced breast cancer and hormone-resistant metastatic breast tumors $(1,15)$.

Unfortunately, resistance to chemotherapy occurs frequently (15). Drug-resistant tumors often become unresponsive to the use of other antitumor therapies, acquire multidrug resistance, and fail to respond to radiation therapy (8). Frequently, the use of chemotherapy drugs as radiation sensitizers fails for unknown reasons $(28,29)$. Overall, data are scarce on the radiation response of drug-resistant cells. Therefore, we set out to dissect the mechanisms of radiation responses of cells resistant to doxorubicin.

Doxorubicin is widely used in curative-intent adjuvant breast cancer therapy (58). Mechanistically, doxorubicin, an anthracycline antibiotic, intercalates DNA and inhibits the progression of the enzyme topoisomerase $2 \alpha$ (Top2A) (58). Functionally, it stabilizes the Top2A complex after it has broken the DNA chain, preventing DNA resealing and, thereby, blocking replication (59). Therefore, because doxorubicin treatment leads to the induction of strand breaks, we hypothesized that cells exposed to doxorubicin for a prolonged period of time could develop structures to effectively repair DSBs, thus avoiding drug-induced apoptosis. Consequently, these structures may help drug-resistant cells withstand the effects of other treatment modalities that induce DNA strand breaks as the primary method of their cell-killing action.

The purpose of this study was to investigate the radiation-induced gene expression changes in the two cell lines of breast adenocarcinoma: the parental MCF-7 and drug-resistant MCF-7/DOX. Using microarray technology tools, we were able to screen the differential gene expression between MCF-7 and MCF-7/DOX. Here, we report the substantial variations in the expression levels of most housekeeping genes between the drug-sensitive and drug-resistant cells.

Housekeeping, or maintenance, genes control basic metabolic functions, provide support through the cell cycle, and are expected to retain an unchanged expression through various cells and tissues during cell development, treatment or disease anomalies (60). This makes housekeeping genes a good reference for the normalization of gene expression analysis following differential treatments or during disease states. However, multiple studies found inconsistent reliabilities in the housekeeping genes as the standard in cancer experiments. Variability in housekeeping gene expression was reported in colorectal, esophageal, gastric, hepatic, breast and prostate cancers (60-63). In our study the expression level of most housekeeping genes in MCF-7/DOX cells was at least six times lower than that in MCF-7 cells (Fig. 1A). We believe that these differences not only reflect the need for a cautious approach when studying differential gene expression, but also can be involved in any 
cellular or tissue changes in the morphology, physiology and sensitivity to treatment modalities. MCF-7/DOX cells were previously characterized as larger than initial MCF-7 cells with stronger adhesion, more complex structural organization due to microtubule and microfilament increases, and the existence of multivesicular bodies near the plasma membrane that may be associated with increased drug efflux (64).

Furthermore, the background differential gene expression was evaluated in unexposed MCF-7/DOX cells, which allowed us to identify possible changes in the biological processes and pathways during the development of drug resistance. Four genes encoding for the ATP-binding cassettes of MDR and MRP subfamilies of $\mathrm{ABC}$ transporters were upregulated in MCF-7/DOX cells compared to the MCF-7cells (Fig. 1B). The overexpression of $\mathrm{ABC}$ transporters is a well-characterized structure of acquired drug resistance in cancer cells, particularly in MCF-7/DOX $(32,65)$.

In addition, 6 genes involved in drug metabolism were upregulated in MCF-7/DOX cells. One of these genes was microsomal glutathione S-transferase 3 (GST), a radical scavenger that is involved in the metabolism of xenobiotics. It was previously found that GST plays an important role in the acquisition of DOX resistance through decreased intracellular drug accumulation and the stimulation of the repair of drug-induced DNA damage $(66,67)$. Moreover, GST may be involved in the resistance of cancer cells to radiation, and therefore, may be considered one of the common structural indicators for chemoand radio-resistance. An early study on human lung cancer cells showed that the introduction of GST cDNA into cells modestly increased resistance to ionizing radiation and adriamycin (68).

The gene profiling analysis showed higher rates of the metabolism of sphingolipids, starch, sucrose, retinol, riboflavin, amino-sugars, nucleo-sugars, androgen and estrogen. We assume that high metabolic rates may also contribute to drug- and radio-resistance and the overall survival ability of cancer cells. It is important to analyze the cellular metabolism in relation to mitochondrial functions.

Eleven genes that play a role in oxidative phosphorylation were highly downregulated in MCF-7/DOX cells. Amongst them are ATP synthases, proton-transporting mitochondrial complexes, NADH dehydrogenases, and a cytochrome $c$ oxidase subunit. These data correlate highly with the previously formulated parameters for drug-resistant cells: i) lower mitochondrial membrane potential; ii) smaller proton gradient and proton leak; iii) higher use of fat for fuel in mitochondria and higher rate of glycolysis; and iv) lower levels of reactive oxygen and lower DNA damage and susceptibility to apoptosis under stress (69). According to the authors, drug- and radiation-resistant cancer cells switch their metabolism (Warburg effect) from efficient respiration to highly inefficient glycolysis, producing ATP to protect themselves from reactive oxygen species. The combination of high glucose utilization, a shift to fatty acids as a source of fuel, and low oxidative phosphorylation is one structure of dual drug- and radio-resistance (69,70).

With the help of David software, we were able to reveal the activation of the MAPK pathway and at least 12 genes from the pathway that contribute to cancer in MCF-7/DOX. These results correlate with a recent study that found that the inhibition of certain cell signaling pathways, including MAPK, inhibited the invasive activities of MCF-7/DOX cells (71). The most upregulated genes were: catenin (Wnt pathway), glycogen synthase kinase $3 \beta$ (Wnt, Hedgehog, ErbB pathways), peroxisome proliferator-activated receptor $\delta$ (Wnt, PPAR pathways), son of sevenless (ErbB, Jak-STAT signaling pathways), and a platelet-derived growth factor receptor (MAPK, focal adhesion, gap junction). We believe that the difference between MCF-7/DOX and its parental line may also contribute to the observed higher invasiveness of drug-resistant cells.

Surprisingly, doxorubicin-resistant MCF-7 cells showed an upregulated expression of at least 47 genes involved in immune response (Table I). Most of the genes are involved in hematopoietic cell lineage, B cell receptor signaling pathways, natural killer cell mediated cytotoxicity, antigen processing and presentation processes or encode components of complement cascades and Ig-like receptors.

Anticancer drugs that induce immune responses are considered to be very successful for cancer treatment. The traditional view states that drug or radiation damage may cause cell surface changes that are recognized by the immune system. The ability of anticancer drugs to boost the host's immune system against tumor cells may have great therapeutic potential (72). Such immunomodulating effects were shown for doxorubicin as well. The doxorubicin-cured mice had memory $\mathrm{T}$ cell-dependent resistance to the reimplantation of the tumor (73). In contrast, therapy-resistant cells display certain molecular and metabolic characteristics that mask them from the immune system. Based on our results, we can speculate that doxorubicin-resistant cells express modified cytokines and cell surface receptors that may recruit the immune system to work for them. We assume that this ability may defend resistant cells against harm due to repeated similar or different treatments. The upregulation of endocytosis, lysosome and proteolysis pathways in MCF-7/DOX may also confirm the unique protective and metabolic characteristics of the drug-resistant cells.

Two key mismatch repair genes, MLH1 and MSH3, along with four base excision repair genes were highly downregulated in MCF-7/DOX cells compared to MCF-7 cells. Meanwhile, six genes encoded for transcription factors, including three members (TAF10, TAF15 and TAF3) of basal transcription factor TAFIID and three cell cycle components, were found to be upregulated in MCF-7/DOX (Fig. 1B). We assume the possibility that the inaccurate repair of nucleotide misincorporation toward fast DNA replication and cell division may result in MCF-7/DOX resistance. Interestingly, MCF-7/DOX cells exhibited low expressions of ribosome subunits and splicing components. The selective inhibition of RNA and protein synthesis may be characteristic of drug-resistant cells, but we are unable to explain this phenomenon in the present research; however, more studies are required in this field.

The main purpose of this study was to examine and compare the radiation responses of drug-sensitive MCF-7 cells and doxorubicin-resistant MCF-7/DOX cells. Gene expression profiling showed that the expression level of more than 500 genes was changed in the sensitive cell line due to 5 Gy X-rays; however in MCF-7/DOX cells, no changes in gene expression were observed. We believe that the ability of the cells to retain their gene expression potential on a constant level regardless of DNA-damaging insults may be due to the features that cells acquired during drug resistance and are shared in other forms of resistance, such as radio resistance. 
MCF-7 cells exhibited the expected downregulation of biological pathways, such as cell cycle, DNA replication, DNA repair and the activation of the p53 pathway (Fig. 1C). Thirty-two cell cycle regulators where downregulated, which led to cell cycle shut down. These genes were encoded for cyclins (A2, B1, B2), cyclin-dependant kinases (CDK2, CDK4), cell division cycle proteins (CDC20, CDC25A, CDC7), E2F transcription factors (E2F2, E2F4), mitotic polo-like kinase PLK1, checkpoint kinase CHEK1, mini-chromosome maintenance complex components (MCM2, 3, 4, 5, 6, 7), and other cell cycle-associated proteins.

The upregulation of the transforming growth factor- $\beta$ (TGF- $\beta$ ) and growth arrest and DNA damage-inducible factors (GADD45A and GADD45G) also contributed to cell cycle deactivation. Obviously, cell cycle deactivation paralleled inhibited DNA replication. Twenty-three genes involved in replication were downregulated: DNA polymerases [A1, A2, D1, D2, E, E2, E3 (except of D4, which was upregulated)], replication factors (RFC2, 3, 4, 5), replication protein (RPA2), mini-chromosome maintenance complex components (MCM2, 3, 4, 5, 6, 7), ligase 1, endonuclease FEN and ribonucleaseH2 (RNASEH2A).

A specialized DNA damage response was initiated through the activation of the p53 pathway due to the overexpression of BCL2-associated $\mathrm{X}$ protein (BAX), damage-specific DNA-binding protein (DDB2), sestrin1 (SESN1), and growth arrest and DNA damage-inducible factors (GADD45A and GADD45G). DNA repair processes were downregulated due primarily to the decrease in the expression of specific repair polymerases and replication factors. For instance, base excision repair downregulation was caused by a low expression of polymerases (D1, D2, E, E2, E3), uracil-DNA glycosylase (UNG), ligase 1 (LIG1) and endonuclease (FEN1); NER deficiency was due to the same polymerases and ligase 1 , and also replication factors (RFC2, 3, 4, 5) and RPA2; MMR deactivation was caused by a low level of MSH6, polymerases D1 and D2, LIG1, RPA2, RFC2, 3, 4, 5, and exonuclease 1 (EXO1); and decreased homologous recombination was caused by low expression levels of RAD54L, XRCC3, polymerases D1 and D2, RPA2, Bloom syndrome, RecQ helicase-like (BLM) and topoisomerase (TOP3A).

Gene expression profiling data were confirmed through the qRT-PCR analysis of six genes that were changed in MCF-7 cells after radiation treatment. Polymerases A, D and $\mathrm{E}$ were involved in most of the biological processes that were affected in MCF-7 cells after radiation exposure (Fig. 1C). Because GADD45G, cyclin A and aurora B are involved in DNA damage responses, cell cycle and cell division, their expression levels were of great interest to us as well.

The members of the aurora kinase family have been actively studied as mitotic progression targets in cancer studies. Mutations associated with aurora gene amplification were reported in human cancers (74). Tumor development and progression due to aberrant chromosomal segregation and aneuploidy is a common outcome of the misregulation of the aurora B function (75).

Inhibition of aurora B during the fractionated radiation treatment suppressed the repopulation of human cancer cells (76). Similarly, 5 Gy X-rays caused a significant downregulation of aurora $B$ in drug-sensitive cell lines, which was correlated with slower mitotic progression and the suppressed repopulation of the cells. Cyclin A expression was also decreased, which may be associated with a lower DNA replication status and suppressed cell cycle progression. In addition, GADD45G, which is a member of growth arrest and DNA-damage inducible genes, was overexpressed after both 0.5 and $5 \mathrm{~Gy}$ of irradiation. This indicates the existence of radiation stress in the cells, which can result in cell cycle arrest, senescence and apoptosis (77).

Significant downregulation of polymerases A, D and E confirms the suppression of DNA replication and DNA repair processes. Overall, gene expression profiling and qRT-PCR analysis showed a strong response in MCF-7 cells to genotoxic agents, such as ionizing radiation, allowing us to conclude that the parental cells were radiation-sensitive. In contrast, the MCF-7/DOX cells did not respond to X-rays on the gene expression level, which signifies that they are radio-resistant. We assume that this radio-resistance was gained in parallel with the acquired resistance to doxorubicin.

All types of DNA repair involve the resynthesis of DNA to replace the damaged strands. Therefore, DNA polymerases play key roles not only in the DNA replication, but also in DNA repair processes $(53,56)$. Specifically, the high fidelity and processivity of polymerases is crucial for faithful DNA replication and the prevention of the accumulation of mutations. Indeed, the efficient repair of DNA synthesis depends on the proper functioning of DNA polymerases. Eukaryotic cells have 15 polymerases that belong to several families $(43,44)$. Members of the B-family of polymerases include the major eukaryotic DNA polymerases $\alpha, \delta$ and $\varepsilon(43,44,78)$. Polymerases $\delta$ and $\varepsilon$ harbor exonuclease activity (43). They take part in the replication and processing of Okazaki fragments during replication processes and are implicated in the repair of damaged DNA. As components of recombination complexes, they are able to repair double-strand breaks and participate in HR and NHEJ.

Some members of the $\mathrm{X}$ family of polymerases, such as polymerase $\beta$, are required for base excision repair. Polymerase $\beta$ is not as accurate as replicative DNA polymerases because it lacks proofreading capability. Polymerase $\beta$ is a key player in base excision repair; it is a mechanism that takes care of damaged bases and single strand breaks $(43,44,79)$. In addition to replicative polymerases, there are a number of translesion DNA polymerases, such as polymerase $\iota$, which is another member of $\mathrm{X}$ family of polymerases. These polymerases are involved in bypassing DNA lesions that otherwise impede replication polymerases (80).

A detailed analysis of DNA polymerases $\delta, \varepsilon, \beta$ and $\mathrm{t}$ demonstrated higher activity but lower fidelity of polymerases in MCF-7/DOX-resistant cells in comparison to MCF-7 cells (Figs. 2 and 3). Low fidelity polymerases are thought to be an evolutionary solution, allowing for the replication of previously damaged DNA and avoiding apoptosis $(81,82)$. The ability to catalyze error-prone DNA synthesis belongs to DNA polymerase $\mathrm{\iota}$, which was highly expressed in doxorubicin-resistant cells and was not detected in parental MCF-7 cells (Figs. 2 and 3).

We also found higher exonuclease/proofreading activity in MCF-7 cells than in MCF-7/DOX cells. In the current study, we only analyzed four cellular DNA polymerases; therefore, future analysis of other polymerases may shed more light on the structure of chemo- and radiation-resistance. This study 
revealed that drug-resistant MCF-7/DOX cells experienced more rapid DNA repair, seemingly sacrificing the specificity and efficiency of this process to gain higher survival potential. In the long run, this may lead to an increased probability of the accumulation of mutations and further the development of an even more pronounced resistance phenotype.

In this study, we assessed the levels of IR-induced apoptosis in MCF-7 and MCF-7/DOX cells. We noted that drug-resistant cells were significantly less susceptible to IR-induced apoptosis than their sensitive counterparts (Fig. 4). We assume that apoptosis delay in MCF-7/DOX cells is a feature of resistance that could be developed by cells after drug treatment. Indeed, it was previously suggested that a drug-induced delay of apoptosis is considered a signifier for pleiotropic drug resistance in tumor cells (83).

Seeking to explain this apparent discrepancy in the levels of IR-induced apoptosis, we studied the formation and repair of DNA damage, including DSBs, using a Comet assay and the induction of $\gamma \mathrm{H} 2 \mathrm{AX}$ foci in MCF-7 and MCF-7/DOX cells after IR exposure. Both methods showed a rapid increase in DNA damage 30 min after radiation treatment in both cell types (Figs. 5 and 6). The level of damage was lowered 24 and $48 \mathrm{~h}$ after exposure, and increased efficiency was found in MCF-7/DOX (Fig. 5). Importantly, the background number of $\gamma \mathrm{H} 2 \mathrm{AX}$ foci in untreated MCF-7 cells correlated with previous study data (40).

The $\gamma \mathrm{H} 2 \mathrm{AX}$ foci appear in the nuclei within 1 min of irradiation and reach their maximum concentration by $30 \mathrm{~min}$ to $1 \mathrm{~h}$. Afterward, the number of $\gamma \mathrm{H} 2 \mathrm{AX}$ foci reduces due to the repair processes $(48,84)$. Our assay showed that non-resistant MCF-7 cells are more radiosensitive (Fig. 6). MCF-7 cells were not able to completely repair DNA damages after high dose ( $5 \mathrm{~Gy}$ ) treatments, and even after $48 \mathrm{~h}$, the amount of residual foci was very high. In contrast, drug-resistant MCF-7/DOX cells did not accumulate substantial damage after low dose $(0.5 \mathrm{~Gy})$ treatments. The maximum number of foci was observed $30 \mathrm{~min}$ after 5 Gy X-ray exposure and was significantly lower than the number of foci detected in MCF-7 cells at this dose. Moreover, all DNA damage in the drug-resistant MCF-7/DOX cells was repaired within $48 \mathrm{~h}$ (Fig. 6). Currently, it is thought that $\gamma \mathrm{H} 2 \mathrm{AX}$ recruits proteins to repair DNA damage and $\gamma \mathrm{H} 2 \mathrm{AX}$ is dephosporylated after the repair is complete (54). Therefore, we assume that the faster foci disappear, the higher the DNA repair activity in the cells.

DSBs can be repaired by two major processes: homologous recombination (HR) and non-homologous end-joining (NHEJ) $(53,56,85)$. HR allows cells to use the undamaged sister chromatid or the homologous chromosome as a template for repair and is considered error-free $(50-53,56)$. The error-free HR is controlled by the RAD51 protein $(50,55,86,87)$. RAD51 binds to single-stranded DNA and forms a nucleoprotein filament that catalyses homology searching, strand pairing, and strand exchange $(86,88)$.

NHEJ is a fast, error-prone process of linking broken DNA ends together without reference to accurate base pairing $(53,56)$. This DNA repair process is most common in mammalian cells and requires a DNA-binding component-heterodimer of KU70 and KU80 proteins $(56,57)$. A crucial signalling component for both pathways is the protein kinase ATM. ATM coordinates DNA repair by phosphorylating the downstream proteins involved in the actual repair (89). The ATM activity is increased 2.0 to 3.0 -fold after exposure to IR (90). Such an increase in ATM activity is thought to occur due to the autophosphorylation of serine 1981 (90).

Our study showed that MCF-7 and drug-resistant MCF-7/DOX cell lines have different profiles of the aforementioned DNA repair proteins. Although both cell lines exhibited elevated levels of pATM, RAD51 and KU70 after exposure, the initial pre-treatment levels of these proteins were different in MCF-7 and MCF-7/DOX cells (Fig. 7). The cytoplasmic localization of ATM in MCF-7/DOX cells was unusual, and it is, at the moment, difficult to explain. The recent report that ATM can be activated in cytoplasm by reactive oxygen species (ROS) could possibly suggest that the cytoplasmic pATM in MCF-7/ DOX cells was activated by ROS generated during doxorubicin treatment (91).

We found that MCF-7 cells express higher levels of KU70, which is a key protein for NHEJ, while doxorubicin-resistant MCF-7/DOX cell elevation of RAD51 could contribute to HR-mediated DNA repair (Fig. 8). Why MCF-7 and MCF-7/ DOX cells display different preferences to error-free and error-prone DSB repair strategies remains unknown, but it is possible, that rapidly dividing MCF-7/DOX cells remain in S and $\mathrm{M}$ phases more often, allowing them to use the present sister chromatids for the repair of DNA damage. Nevertheless, we believe that triggering certain steps of preferred repair pathways may improve chemo- and radiotherapy responses. Our data are in agreement with previous studies, showing higher DNA repair potential in drug-resistant cells $(20,21,23,27,92)$.

Further detailed studies are needed to determine the cellular and molecular processes that are altered in resistant cells that allow them to survive genotoxic treatments, such as irradiation. This study may, therefore, provide a roadmap for the analysis of the roles of DNA repair function and effectiveness, and apoptosis in responses to radiation, chemotherapy and combinations of both treatment modalities.

\section{Acknowledgements}

We are grateful to Rocio Rodriguez-Juarez, Jody Filkowski and Dipankar Goyal for technical assistance. This study was supported by Alberta Cancer Research Institute grant to O. Kovalchuk. L. Luzhna is a recipient of the Alberta Cancer Research Institute Graduate Scholarship.

\section{References}

1. Guarneri V and Conte PF: The curability of breast cancer and the treatment of advanced disease. Eur J Nucl Med Mol Imaging 31 (Suppl 1): S149-S161, 2004.

2. Lehnert M: Clinical multidrug resistance in cancer: a multifactorial problem. Eur J Cancer 32A: 912-920, 1996.

3. Szakacs G, Paterson JK, Ludwig JA, Booth-Genthe C and Gottesman MM: Targeting multidrug resistance in cancer. Nat Rev Drug Discov 5: 219-234, 2006.

4. Fojo T: Multiple paths to a drug resistance phenotype: mutations, translocations, deletions and amplification of coding genes or promoter regions, epigenetic changes and microRNAs. Drug Resist Updat 10: 59-67, 2007.

5. O'Driscoll L and Clynes M: Molecular markers of multiple drug resistance in breast cancer. Chemotherapy 52: 125-129, 2006.

6. Gottesman MM: Mechanisms of cancer drug resistance. Annu Rev Med 53: 615-627, 2002. 
7. Pommier Y, Sordet O, Antony S, Hayward RL and Kohn KW: Apoptosis defects and chemotherapy resistance: molecular interaction maps and networks. Oncogene 23: 2934-2949, 2004

8. Stavrovskaya AA: Cellular mechanisms of multidrug resistance of tumor cells. Biochemistry (Mosc) 65: 95-106, 2000.

9. Karran P: Mechanisms of tolerance to DNA damaging therapeutic drugs. Carcinogenesis 22: 1931-1937, 2001.

10. Rixe $\mathrm{O}$ and Fojo $\mathrm{T}$ : Is cell death a critical end point for anticancer therapies or is cytostasis sufficient? Clin Cancer Res 13 : 7280-7287, 2007.

11. Hickman JA: Apoptosis and chemotherapy resistance. Eur J Cancer 32A: 921-926, 1996.

12. Gottesman MM and Ling V: The molecular basis of multidrug resistance in cancer: the early years of P-glycoprotein research. FEBS Lett 580: 998-1009, 2006.

13. Modok S, Mellor HR and Callaghan R: Modulation of multidrug resistance efflux pump activity to overcome chemoresistance in cancer. Curr Opin Pharmacol 6: 350-354, 2006.

14. Coley HM: Mechanisms and strategies to overcome chemotherapy resistance in metastatic breast cancer. Cancer Treat Rev 34: 378-390, 2008.

15. Gonzalez-Angulo AM, Morales-Vasquez F and Hortobagyi GN: Overview of resistance to systemic therapy in patients with breast cancer. Adv Exp Med Biol 608: 1-22, 2007.

16. Petrelli A and Giordano S: From single- to multi-target drugs in cancer therapy: when aspecificity becomes an advantage. Curr Med Chem 15: 422-432, 2008

17. Chekhun VF, Lukyanova NY, Kovalchuk O, Tryndyak VP and Pogribny IP: Epigenetic profiling of multidrug-resistant human MCF-7 breast adenocarcinoma cells reveals novel hyper- and hypomethylated targets. Mol Cancer Ther 6: 1089-1098, 2007.

18. Dean-Colomb W and Esteva FJ: Emerging agents in the treatment of anthracycline- and taxane-refractory metastatic breast cancer. Semin Oncol 35: S31-S40, 2008.

19. Ozols RF, Masuda $\mathrm{H}$ and Hamilton TC: Mechanisms of cross-resistance between radiation and antineoplastic drugs. NCI Monogr pp159-165, 1988

20. Shimm DS, Olson S and Hill AB: Radiation resistance in a multidrug resistant human T-cell leukemia line. Int J Radiat Oncol Biol Phys 15: 931-936, 1988.

21. Belli JA: Interaction between radiation and drug damage in mammalian cells. IV. Radiation response of adriamycinresistant V79 cells. Radiat Res 119: 88-100, 1989.

22. Lehnert S, Greene D and Batist G: Radiation response of drug-resistant variants of a human breast cancer cell line. Radiat Res 118: 568-580, 1989.

23. Lehnert S, Greene D and Batist G: Radiation response of drug-resistant variants of a human breast cancer cell line: the effect of glutathione depletion. Radiat Res 124: 208-215, 1990.

24. Alaoui-Jamali MA, Batist G and Lehnert S: Radiation-induced damage to DNA in drug- and radiation-resistant sublines of a human breast cancer cell line. Radiat Res 129: 37-42, 1992.

25. Miller PR, Hill AB, Slovak ML and Shimm DS: Radiation resistance in a doxorubicin-resistant human fibrosarcoma cell line. Am J Clin Oncol 15: 216-221, 1992.

26. Zhang Y, Sweet KM, Sognier MA and Belli JA: Interaction between radiation and drug damage in mammalian cells. VI Radiation and doxorubicin age-response function of doxorubicin-sensitive and -resistant Chinese hamster cells. Radiat Res 132: 105-111, 1992

27. Lehnert S, Vestergaard J, Batist G and Aloui-Jamali MA: Radiation resistance in a melphalan-resistant subline of a rat mammary carcinoma. Radiat Res 139: 232-239, 1994.

28. Liang K, Lu Y, Jin W, Ang KK, Milas L and Fan Z: Sensitization of breast cancer cells to radiation by trastuzumab. Mol Cance Ther 2: 1113-1120, 2003.

29. Koukourakis MI, Koukouraki S, Giatromanolaki A, et al: Liposomal doxorubicin and conventionally fractionated radiotherapy in the treatment of locally advanced non-small-cell lung cancer and head and neck cancer. J Clin Oncol 17: 3512-3521, 1999.

30. Gewirtz DA: Growth arrest and cell death in the breast tumor cell in response to ionizing radiation and chemotherapeutic agents which induce DNA damage. Breast Cancer Res Treat 62 223-235, 2000

31. Reinhold WC, Kouros-Mehr H, Kohn KW, et al: Apoptotic susceptibility of cancer cells selected for camptothecin resistance: gene expression profiling, functional analysis, and molecular interaction mapping. Cancer Res 63: 1000-1011, 2003 .
32. Kovalchuk O, Filkowski J, Meservy J, et al: Involvement of microRNA-451 in resistance of the MCF-7 breast cancer cells to chemotherapeutic drug doxorubicin. Mol Cancer Ther 7: 2152-2159, 2008

33. Huang da W, Sherman BT and Lempicki RA: Systematic and integrative analysis of large gene lists using DAVID bioinformatics resources. Nat Protoc 4: 44-57, 2009.

34. Huang da W, Sherman BT and Lempicki RA: Bioinformatics enrichment tools: paths toward the comprehensive functional analysis of large gene lists. Nucleic Acids Res 37: 1-13, 2009.

35. Pfaffl MW: A new mathematical model for relative quantification in real-time RT-PCR. Nucleic Acids Res 29: e45, 2001

36. Tryndyak VP, Kovalchuk O and Pogribny IP: Loss of DNA methylation and histone $\mathrm{H} 4$ lysine 20 trimethylation in human breast cancer cells is associated with aberrant expression of DNA methyltransferase 1, Suv4-20h2 histone methyltransferase and methyl-binding proteins. Cancer Biol Ther 5: 65-70, 2006.

37. Gening LV, Petrochenkov AN, Reshetnyak AB, Andreeva LE and Tarantul VZ: DNA polymerase iota-like activity in crude cell extracts of different mouse organs. Biochemistry (Mosc) 69: 435-440, 2004.

38. Olive PL and Banath JP: The comet assay: a method to measure DNA damage in individual cells. Nat Protoc 1: 23-29, 2006.

39. Tice RR and Strauss GH: The single cell gel electrophoresis/comet assay: a potential tool for detecting radiation-induced DNA damage in humans. Stem Cells 13 (Suppl 1): 207-214, 1995.

40. Sedelnikova OA and Bonner WM: GammaH2AX in cancer cells: a potential biomarker for cancer diagnostics, prediction and recurrence. Cell Cycle 5: 2909-2913, 2006.

41. Carpenter AE, Jones TR, Lamprecht MR, et al: CellProfiler: image analysis software for identifying and quantifying cell phenotypes. Genome Biol 7: R100, 2006.

42. Lamprecht MR, Sabatini DM and Carpenter AE: CellProfiler: free, versatile software for automated biological image analysis. Biotechniques 42: 71-75, 2007.

43. Bebenek K and Kunkel TA: Functions of DNA polymerases. Adv Protein Chem 69: 137-165, 2004.

44. Shcherbakova PV, Bebenek K and Kunkel TA: Functions of eukaryotic DNA polymerases. Sci Aging Knowledge Environ 2003: RE3, 2003

45. Vermes I, Haanen C, Steffens-Nakken H and Reutelingsperger C: A novel assay for apoptosis. Flow cytometric detection of phosphatidylserine expression on early apoptotic cells using fluorescein labelled Annexin V. J Immunol Methods 184: 39-51, 1995.

46. Little JB: Radiation carcinogenesis. Carcinogenesis 21: 397-404, 2000.

47. Huang L, Snyder AR and Morgan WF: Radiation-induced genomic instability and its implications for radiation carcinogenesis. Oncogene 22: 5848-5854, 2003.

48. Bonner WM, Redon CE, Dickey JS, et al: GammaH2AX and cancer. Nat Rev Cancer 8: 957-967, 2008.

49. Olive PL: DNA damage and repair in individual cells: applications of the comet assay in radiobiology. Int J Radiat Biol 75: 395-405, 1999.

50. West SC: Molecular views of recombination proteins and their control. Nat Rev Mol Cell Biol 4: 435-445, 2003.

51. McGlynn P and Lloyd RG: Recombinational repair and restart of damaged replication forks. Nat Rev Mol Cell Biol 3: 859-870, 2002.

52. Helleday T: Pathways for mitotic homologous recombination in mammalian cells. Mutat Res 532: 103-115, 2003.

53. Hoeijmakers JH: DNA repair mechanisms. Maturitas 38: 17-23, 2001.

54. Chowdhury D, Keogh MC, Ishii H, Peterson CL, Buratowski S and Lieberman J: gamma-H2AX dephosphorylation by protein phosphatase 2A facilitates DNA double-strand break repair. Mol Cell 20: 801-809, 2005.

55. Lundin C, Schultz N, Arnaudeau C, Mohindra A, Hansen LT and Helleday T: RAD51 is involved in repair of damage associated with DNA replication in mammalian cells. J Mol Biol 328: $521-535,2003$.

56. Hoeijmakers JH: Genome maintenance mechanisms for preventing cancer. Nature 411: 366-374, 2001

57. Jin S and Weaver DT: Double-strand break repair by Ku70 requires heterodimerization with $\mathrm{Ku} 80$ and DNA binding functions. EMBO J 16: 6874-6885, 1997. 
58. Fornari FA, Randolph JK, Yalowich JC, Ritke MK and Gewirtz DA: Interference by doxorubicin with DNA unwinding in MCF-7 breast tumor cells. Mol Pharmacol 45: 649-656, 1994.

59. Fortune JM and Osheroff N: Topoisomerase II as a target for anticancer drugs: when enzymes stop being nice. Prog Nucleic Acid Res Mol Biol 64: 221-253, 2000.

60. Khimani AH, Mhashilkar AM, Mikulskis A, et al: Housekeeping genes in cancer: normalization of array data. Biotechniques 38: $739-745,2005$.

61. Rubie C, Kempf K, Hans J, et al: Housekeeping gene variability in normal and cancerous colorectal, pancreatic, esophageal, gastric and hepatic tissues. Mol Cell Probes 19: 101-109, 2005 .

62. Barnard GF, Staniunas RJ, Bao S, et al: Increased expression of human ribosomal phosphoprotein $\mathrm{P} 0$ messenger RNA in hepatocellular carcinoma and colon carcinoma. Cancer Res 52: 3067-3072, 1992.

63. Henry JL, Coggin DL and King CR: High-level expression of the ribosomal protein L19 in human breast tumors that overexpress erbB-2. Cancer Res 53: 1403-1408, 1993.

64. Lukyanova NY, Rusetskya NV, Tregubova NA and Chekhun VF: Molecular profile and cell cycle in MCF-7 cells resistant to cisplatin and doxorubicin. Exp Oncol 31: 87-91, 2009.

65. Gyorffy B, Serra V, Jurchott K, et al: Prediction of doxorubicin sensitivity in breast tumors based on gene expression profiles of drug-resistant cell lines correlates with patient survival. Oncogene 24: 7542-7551, 2005.

66. Huang J, Tan PH, Thiyagarajan J and Bay BH: Prognostic significance of glutathione S-transferase-pi in invasive breast cancer. Mod Pathol 16: 558-565, 2003.

67. Saleh EM, El-Awady RA, Abdel Alim MA and Abdel Wahab AH: Altered expression of proliferation-inducing and proliferation-inhibiting genes might contribute to acquired doxorubicin resistance in breast cancer cells. Cell Biochem Biophys 55: 95-105, 2009.

68. Miyara H, Hida T, Nishida K, et al: Modification of chemoradiosensitivity of a human lung cancer cell line by introduction of the glutathione S-transferase pi gene. Jpn J Clin Oncol 26 : $1-5,1996$.

69. Harper ME, Antoniou A, Villalobos-Menuey E, et al: Characterization of a novel metabolic strategy used by drug-resistant tumor cells. FASEB J 16: 1550-1557, 2002.

70. Diehn M, Cho RW, Lobo NA, et al: Association of reactive oxygen species levels and radioresistance in cancer stem cells. Nature 458: 780-783, 2009.

71. Kang JH, Song KH, Jeong KC, et al: Involvement of Cox-2 in the metastatic potential of chemotherapy-resistant breast cancer cells. BMC Cancer 11: 334, 2011.

72. Mihich E: On the immunomodulating effects of anti-cancer drugs and their therapeutic exploitation. Jpn J Clin Oncol 30: 469-471, 2000

73. Ehrke MJ, Verstovsek S,Zaleskis G, et al: Specific anti-EL4-lymphoma immunity in mice cured 2 years earlier with doxorubicin and interleukin-2. Cancer Immunol Immunother 42: 221-230, 1996.

74. Cahill DP, Lengauer C, Yu J, et al: Mutations of mitotic checkpoint genes in human cancers. Nature 392: 300-303, 1998.
75. Nguyen HG, Makitalo M, Yang D, Chinnappan D, St Hilaire C and Ravid K: Deregulated Aurora-B induced tetraploidy promotes tumorigenesis. FASEB J 23: 2741-2748, 2009.

76. Sak A, Stuschke M, Groneberg M, Kubler D, Pottgen C and Eberhardt WE: Inhibiting the aurora B kinase potently suppresses repopulation during fractionated irradiation of human lung cancer cell lines. Int J Radiat Oncol Biol Phys 84: 492-499, 2012

77. Liebermann DA, Tront JS, Sha X, Mukherjee K, MohamedHadley A and Hoffman B: Gadd45 stress sensors in malignancy and leukemia. Crit Rev Oncog 16: 129-140, 2011.

78. Kunkel TA and Burgers PM: Dividing the workload at a eukaryotic replication fork. Trends Cell Biol 18: 521-527, 2008.

79. Matsuda T, van de Berg BJ, Bebenek K, Osheroff WP, Wilson SH and Kunkel TA: The base substitution fidelity of DNA polymerase beta-dependent single nucleotide base excision repair. J Biol Chem 278: 25947-25951, 2003.

80. Kunkel TA, Pavlov YI and Bebenek K: Functions of human DNA polymerases eta, kappa and iota suggested by their properties, including fidelity with undamaged DNA templates. DNA Repair (Amst) 2: 135-149, 2003.

81. Beard WA, Shock DD, Vande Berg BJ and Wilson SH: Efficiency of correct nucleotide insertion governs DNA polymerase fidelity. J Biol Chem 277: 47393-47398, 2002.

82. Goodman MF and Tippin B: Sloppier copier DNA polymerases involved in genome repair. Curr Opin Genet Dev 10: 162-168, 2000.

83. Taylor ST, Hickman JA and Dive C: Survival signals within the tumour microenvironment suppress drug-induced apoptosis: lessons learned from B lymphomas. Endocr Relat Cancer 6: 21-23, 1999.

84. Banath JP, Macphail SH and Olive PL: Radiation sensitivity, $\mathrm{H} 2 \mathrm{AX}$ phosphorylation, and kinetics of repair of DNA strand breaks in irradiated cervical cancer cell lines. Cancer Res 64: 7144-7149, 2004.

85. Jeggo $\mathrm{P}$ and Lobrich M: Radiation-induced DNA damage responses. Radiat Prot Dosimetry 122: 124-127, 2006.

86. Baumann P and West SC: Role of the human RAD51 protein in homologous recombination and double-stranded-break repair. Trends Biochem Sci 23: 247-251, 1998.

87. Dudas A and Chovanec M: DNA double-strand break repair by homologous recombination. Mutat Res 566: 131-167, 2004.

88. Benson FE, Baumann P and West SC: Synergistic actions of Rad51 and Rad52 in recombination and DNA repair. Nature 391: 401-404, 1998.

89. Goodarzi AA, Block WD and Lees-Miller SP: The role of ATM and ATR in DNA damage-induced cell cycle control. Prog Cell Cycle Res 5: 393-411, 2003.

90. Goodarzi AA, Jonnalagadda JC, Douglas P, et al: Autophosphorylation of ataxia-telangiectasia mutated is regulated by protein phosphatase 2A. EMBO J 23: 4451-4461, 2004.

91. Alexander A, Cai SL, Kim J, et al: ATM signals to TSC2 in the cytoplasm to regulate mTORC1 in response to ROS. Proc Natl Acad Sci USA 107: 4153-4158, 2010.

92. Harris AL: DNA repair: relationship to drug and radiation resistance, metastasis and growth factors. Int $\mathrm{J}$ Radiat Biol Relat Stud Phys Chem Med 48: 675-690, 1985. 